\title{
Growth and Welfare: Distorting versus Non-Distorting Taxes*
}

\author{
Gustavo A. Marrero and Alfonso Novales ${ }^{\dagger}$ \\ First version june 2002. This version july 2003
}

\begin{abstract}
Some concepts associated with the notion of public consumption could be considered as wasteful public expenditures, so that a firstbest analysis would set their level equal to zero every period. However, their ratio to output is significant and rather stable over time in actual economies. In an endogenous growth framework similar to Barro (1990), we analytically characterize the dependence of a secondbest public investment policy on wasteful public consumption. We compare two extreme tax systems: a distorting system and a nondistorting one. The presence of wasteful expenditures affect optimal public investment and the optimal public financing mechanism. Since private agents do not internalize the fact that by raising their capital accumulation they could be generating extra public investment and consumption, financing public expenditures through lump-sum taxes might lead to an excessive crowding-out impact on current consumption, which may sharply reduce welfare in the short-run as well as limit public capital accumulation and long-run growth. It turns out that this effect can be more damaging for growth and welfare than
\end{abstract}

*We are grateful to Jordi Caballé and John Leahy for helpful discussions and comments. This version benefited from comments from a referee. The first version of the paper was finished while Gustavo A. Marrero was visiting the Economic Department at Boston University. Financial support from the Spanish Ministry of Education (through DGICYT grant no. PB98-0831) is gratefully acknowledged.

${ }^{\dagger}$ Correspondence to: Alfonso Novales, Departamento de Economía Cuantitativa, Universidad Complutense, Somosaguas, 28223 Madrid, Spain. e-mail: anovales@ccee.ucm.es 
the disincentive created on private capital accumulation when taxing capital income.

Keywords: Endogenous growth, distorting taxes, public investment, wasteful public expenditure.

JEL Classification: E0, E6, O4 


\section{Introduction}

Analyzing the implications of fiscal policy for growth and welfare is central to optimal economic policy design. In dynamic settings, we can consider four main branches of research: i) characterizing the impact on growth and welfare of a second-best tax structure, along the lines of the seminal paper by Ramsey (1927) [Chamley (1986), Judd (1985), Lucas (1991), etc.], ${ }^{1}$ ii) analyzing the influence of public investment on growth and welfare, along the lines of Barro (1990) [Futagami et al. (1993), Glomm and Ravikumar (1994), Turnovsky $(1996,2000)$, etc. $]^{2}$ iii) reexamining the idea proposed by Barro (1979) that taxes should follow a smooth process, regardless of the stochastic process followed by government expenditures [Lucas and Stockey (1983), Hansen et al. (1991), etc.], and iv) focusing on fiscal policy as a potential major source of macroeconomic fluctuations [Barro (1981), Baxter and King (1993), etc.].

Somewhat surprisingly, however, not much work has been done regarding the optimal simultaneous choice of a public investment and a financing rule. Some exceptions are Corsetti and Roubini (1996) in a two-sector endogenous growth setting and Fisher and Turnovsky (1998) in a neoclassical growth model, among others. In the former, public expenditures are assumed to exert a positive external effect on physical capital while, in the latter, private capital over-congests public capital in competitive equilibrium. ${ }^{3}$ In these analyses, private capital is over-accumulated at the competitive equilibrium allocation, so it will generally be desirable that a government should abate this over-accumulation by taxing capital rents. ${ }^{4}$ We aim to do some progress

\footnotetext{
${ }^{1}$ These pioneer works by Judd (1985), Chamley (1986) and Lucas (1990) emphasized the negative incidence of capital income taxes on welfare in general equilibrium models. Judd (1999) also argued for a zero tax rate on physical and human capital income in the long-run. In these economies, the public sector is assumed to finance a constant stream of wasteful government spending, and in general raising revenues through taxing factors' rents is baneful for welfare. However, this result clearly depends upon the chance the government has to use alternative financing instruments.

${ }^{2}$ Empirical work by Ratner (1983), Aschauer (1989) and Munnell (1990) emphasizes the positive link between public expenses and the private production process, among many others.

${ }^{3}$ In a model without public capital, Chamley (2001) shows that borrowing constraints may induce individuals to over-accumulate capital in the long-run when insuring against idiosyncratic shocks.

${ }^{4}$ An alternative well-known argument in favor of taxing in a distorting fashion arises from distributive considerations. Generally, the positive effect of income distribution be-
} 
along this line, by characterizing an optimal policy of taxing the income earned by physical capital as a production factor.

A broad classification of public expenditures would distinguish between productive and non-productive concepts. Roughly, public investment could be considered as the productive type of public expenditures [Barro (1990)]. Among the non-productive concepts, there exists those that could be considered wasteful public expenditures, like bureaucratic and administrative costs, the payment of interest on outstanding debt, etc., which we could associate with the notion of public consumption. In the absence of frictions or constraints, a first-best analysis of optimal policy would suggest setting this type of expenditures equal to zero every period. However, what we observe in real economies is that, as a percentage of output, public consumption is far from zero and has remained fairly constant over the last decades. ${ }^{5}$ This suggests the presence of some restrictions in real economies that lead into a second-best choice of public investment and consumption, as well as of their appropriate financing scheme. This is in line with Jones et al. (1997) and Milesi-Ferretti and Roubini (1998), who pointed out that certain public revenue constraints could imply that taxing productive factors positively in the long-run might be optimal in a second-best sense.

Our aim is precisely to characterize the effect of wasteful public expenditures on the optimal public investment policy, as well as on the appropriate financing mechanism for total public expenditures in an endogenous growth framework similar to Barro (1990). In that setting, a) we assume that public and private capital enter the private production process; b) two types of public expenses are considered: public investment, which affects production through the stock of public capital available every period, and public consumption, which does not directly affect utility or production, thereby being some kind of wasteful public expenditure; c) along the balanced growth

tween generations makes a zero tax rate on capital income not to be optimal: see Jones and Manuelli (1992) in an overlapping generations setting with production, and Caballé (1998) in an infinitely-lived framework with altruistic preferences.

${ }^{5}$ On average and along the period $1970-88$ and for a large set of countries, Easterly and Rebelo (1994), pp. 36, show that, as a percentage of GDP, the Current Government Expenditure was 23,4\%, the Gross Fixed Capital Formation 3,3\% and the Capital Expenditure $5,8 \%$. In addition, they show that the standard deviation of the gross fixed capital formation and capital expenditure is almost the same as their means, while it is less than halved for current expenditure. This fact leads us to think that in real economies the path of several concepts of public expenditures are painless to be altered than others (i.e., public investment or expenditure in $\mathrm{R} \& \mathrm{D})$. 
path, public consumption grows at the same rate than output, and it must be financed every period; ${ }^{6} \mathrm{~d}$ ) the same taxing scheme finances both types of public expenditures, while issuing debt is forbidden. Additional assumptions will be introduced transforming our setup into a version of the $A K$ model, which will allow us to solve analytically for the competitive equilibrium.

We analytically characterize the welfare-maximizing public investment/output ratio under two alternative and extreme tax scenarios. These are, for the sake of simplicity, those considered in Fisher and Turnovsky (1998): 1) a distortionary tax on total income (referred to as the distorting tax system hereinafter) and 2) a lump-sum tax (the non-distorting tax system), in both cases with a period-by-period balanced budget. Then, we compute and compare the maximum growth rates and welfare levels achieved under both tax systems. It turns out that the existence of a wasteful component in public expenditures not only affects the optimal public investment policy, but it could also alter dramatically the way how public expenditures should be financed. Indeed, we show that raising revenues through distorting taxation might be a preferred strategy to raising revenues through lump-sum taxation, this result not relying upon the type of externalities described above (borrowing constraints, congestion effects of public capital,...). This result is more likely to arise in economies with high levels of the wasteful public expenditure/output ratio, high values of the elasticities of private and public capital in the private production process and/or a high preference for future utility.

The intuition behind our result is as follows: In a Barro-type setting, a tax increase can be used to finance a higher level of public investment, which has a direct and positive impact on growth and welfare. If the source of revenues is income taxes, private capital accumulation will be discouraged, and the positive effect on growth and welfare of the increase in productive public expenditures is partly neutralized. On the other hand, even though lumpsum tax financing is not harmful for private capital accumulation, private consumption will be strongly affected immediately, since it will experience most of the implied crowding-out impact. That way, choosing between distorting and non-distorting taxes represents a trade-off between current and future consumption. Discouraging private capital accumulation, distorting taxes have a long-run effect on future growth and consumption. Alterna-

\footnotetext{
${ }^{6}$ Since our economy shows ongoing endogenous growth, it has no sense to assume a contant stream of wasteful expenditure.
} 
tively, taxing lump-sum has a strong short-run effect on consumption, with no disincentive on private capital accumulation. Which tax system is preferred will depend on the relative size of both effects on welfare.

Since private agents do not internalize the fact that by increasing output through their private capital accumulation decisions they contribute to generating higher public investment and consumption, the true social cost of this additional output is not being taken into account. Consequently, financing total public expenditures through lump-sum taxes leads to an extra crowding-out impact on current consumption, which may sharply reduce initial welfare and also the growth stimulus achievable through public investment. It turns out that this effect can be more damaging for growth and welfare than the disincentive created on private capital accumulation when taxing capital income.

The paper is organized as follows. In section 2 the basic framework is described. In section 3 the competitive equilibrium and the long-run equilibrium path are characterized. In sections 4 the growth- and welfaremaximizing public investment policies under income and lump-sum taxes are compared, and a simple numerical example is presented. Finally, section 5 ends with main conclusions and extensions.

\section{A basic framework for analysis}

The model draws on work by Barro (1990), Futagami et al. (1993) and Glomm and Ravikumar (1994). It differs from the non-congested version in the Glomm-Ravikumar setting because of the presence of an spillover factor in production and the fact that not all public expenditure is productive. The economy consists of a continuum of identical firms, a fiscal authority and a representative household.

\section{$2.1 \quad$ Firms}

Firms are identical, rent the same amount of physical capital $k_{t}$ and labor $l_{t}$ from households, and produce $y_{t}$ units of the consumption commodity at a given period $t$. The capital stock used in the aggregate by all firms, $K_{t}$, is taken as a proxy for the index of knowledge available to each single firm [as in Romer (1986)]. Additionally, public capital, $K_{t}^{g}$, is exogenous to the private production process and affects all individual firms in the same way. Except 
for these externalities, the private production technology can be represented by a standard Cobb-Douglas function presenting constant returns to scale.

Assumption 1: Private and public capital are essential in the private production process.

The technology available to any firm can be represented,

$$
y_{t}=f\left(l_{t}, k_{t}, K_{t}, K_{t}^{g}\right)=A l_{t}^{1-\alpha} k_{t}^{\alpha} K_{t}^{\phi}\left(K_{t}^{g}\right)^{\theta}, \alpha, \theta \in(0,1), \phi \in[0,1],
$$

where $\alpha$ is the share of private capital in output, $\theta$ and $\phi$ are the constant elasticities of output with respect to public capital and the knowledge index, and $A$ is a technological scale. Since all firms are identical, we can aggregate on (1) to obtain total output in the economy, $Y_{t}$,

$$
Y_{t}=A L_{t}^{1-\alpha} K_{t}^{(\alpha+\phi+\theta)}\left(\frac{K_{t}^{g}}{K_{t}}\right)^{\theta}
$$

where $L_{t}, K_{t}$ are the total amounts of labor and physical capital used by all the firms in the economy. We focus on the special case in which cumulative factors show constant returns to scale. As it is well known [see Barro (1990) and Rebelo (1991), among many others], this is a necessary condition for endogenous growth to arise in a Barro-type setting: ${ }^{7}$

Assumption 2: $\alpha+\phi+\theta=1$.

During period $t$, each firm faces competitive markets for the production factors, were the wage $w_{t}$ and the real interest rate $r_{t}$ are determined. The profit maximizing problem of the typical firm turns out to be static,

$$
\underset{\left\{l_{t}, k_{t}\right\}}{\operatorname{Max}} f\left(l_{t}, k_{t}, K_{t}, K_{t}^{g}\right)-w_{t} l_{t}-r_{t} k_{t},
$$

leading to the usual marginal product conditions,

$$
\begin{aligned}
& r_{t}=f_{k_{t}}^{\prime}=\alpha A l_{t}^{1-\alpha} k_{t}^{\alpha-1} K_{t}^{\phi}\left(K_{t}^{g}\right)^{\theta}=\alpha \frac{y_{t}}{k_{t}}=\alpha \frac{Y_{t}}{K_{t}}, \\
& w_{t}=f_{l_{t}}^{\prime}=(1-\alpha) A l_{t}^{-\alpha} k_{t}^{\alpha} K_{t}^{\phi}\left(K_{t}^{g}\right)^{\theta}=(1-\alpha) \frac{y_{t}}{l_{t}}=(1-\alpha) \frac{Y_{t}}{L_{t}},
\end{aligned}
$$

\footnotetext{
${ }^{7}$ Even though the presence of the spillover factor in the aggregate technology is not needed for our results, it allows us to: i) change the values of the $\alpha, \theta$ parameters independently from each other when conducting a sensitive analysis; ii) pick standard values for $\alpha$ and $\theta$ out in a calibration excercise (0,36 and 0,20 , respectively), by setting $\phi=0,44$. However, considering a broad definition of private capital might allow $\alpha$ to be well above 0,36 , and the spillover effect would not be necessary.
} 
where we have used the fact that each firm treats its own contribution to the aggregate capital stock as given. Under (3)-(4), every firm gets zero profits and we have the standard result on income distribution,

$$
r_{t} K_{t}+w_{t} L_{t}=Y_{t}
$$

\subsection{The public sector}

The public sector collects taxes to finance its expenditures.

Assumption 3: Two types of public expenditures are considered: public investment, $I_{t}^{g}$, and public services, $C_{t}^{g}$, the latter having no incidence on the production technology or the preferences of the representative consumer.

As in Barro (1990), public investment is assumed to be a constant and positive fraction, $\varkappa_{i}$, of total output every period, ${ }^{8}$

$$
I_{t}^{g}=\varkappa_{i} Y_{t}, \varkappa_{i} \geq 0
$$

Public capital accumulates according to,

$$
K_{t+1}^{g}=I_{t}^{g}+\left(1-\delta^{g}\right) K_{t}^{g} .
$$

On the other hand, we consider the following exogenous process for $C_{t}^{g}$.

$$
C_{t}^{g}=C_{0}^{g}\left(1+\gamma_{g}\right)^{t}, C_{0}^{g}, \gamma_{g} \geq 0
$$

where $C_{0}^{g}$ is the initial level of wasteful public expenditures and $\gamma_{g}$ is its constant growth rate. ${ }^{9}$ Under Assumption 2, total output will grow at a constant rate, $\gamma_{y}$, in the long-run. $\gamma_{g}$ can never be bigger than $\gamma_{y}$, since that would make the ratio $C_{t}^{g} / Y_{t}$ raise without any bound. On the other hand, if $\gamma_{g}<\gamma_{y}$ the ratio $C_{t}^{g} / Y_{t}$ would go to zero, preventing us from analyzing the long-run limitations that wasteful public expenditures impose on the choice of optimal fiscal policy. Hence, we assume that $\gamma_{g}=\gamma_{y}$.

Assumption 4: The wasteful component of public expenditures grows every period at the long-run growth rate of output.

\footnotetext{
${ }^{8}$ According to Easterly and Rebelo (1994), the total consolidated public investment/output ratio (public enterprise and general government investment) was 9,17\% (considering the decade averages - 1960's, 70's and 80's - for their cross-section set of countries).

${ }^{9}$ Since our economy will show an ongoing growth process, it has no sense to assume a constant path for $C_{t}^{g}$.
} 
Remark 1 Under Assumption 4, $C_{t}^{g} / Y_{t}$ will converge to a constant ratio $\varkappa_{c}>0$. If we add the assumption that public and private capital fully depreciate every period, our economy is just a version of the AK-model, not displaying any transitional dynamics, so

$$
C_{t}^{g}=\varkappa_{c} Y_{t} \text {, for all } t \geq 0 \text {. }
$$

Remark 2 From (6) and (9), public expenditure is bounded above for any period $t$,

$$
C_{t}^{g}+I_{t}^{g} \leq\left(C_{0}^{g}+I_{0}^{g}\right)\left(1+\gamma_{y}\right)^{t} .
$$

Assumption 5: Tax revenues finance total public expenditures every period.

Two alternative tax scenarios are considered [as in Fisher and Turnovsky (1998)]: $i$ ) a distorting taxation scheme, where total income is taxed at a rate $\tau_{t}$ while transfers, $X_{t}$, are zero, with a government budget constraint,

$$
I_{t}^{g}+C_{t}^{g}=\tau_{t} Y_{t},
$$

and $i i)$ a non-distorting tax scenario, with $\tau_{t}=0$, and the government financing its expenditures through lump-sum taxes,

$$
I_{t}^{g}+C_{t}^{g}=X_{t}
$$

\subsection{Households}

We assume zero population growth and normalize population size to one. The representative consumer is the owner of physical capital, and allocates her resources between consumption, $C_{t}$, and investment in physical capital, $I_{t}$. Private physical capital accumulates over time according to,

$$
K_{t+1}=I_{t}+(1-\delta) K_{t}
$$

and decisions are made each period to maximize the discounted aggregate value of the time separable, logarithmic utility function

$$
\underset{\left\{C_{t}, K_{t+1}\right\}_{t=0}^{\infty}}{\operatorname{Max}} \sum_{t=0}^{\infty} \beta^{t} \ln \left(C_{t}\right),
$$


subject to the budget constraint,

$$
C_{t}+K_{t+1}-(1-\delta) K_{t} \leq\left(1-\tau_{t}\right)\left(w_{t} L_{t}+r_{t} K_{t}\right)
$$

under income taxes and

$$
C_{t}+K_{t+1}-(1-\delta) K_{t}+X_{t} \leq w_{t} L_{t}+r_{t} K_{t}
$$

under lump-sum taxes. $K_{t+1}$ denotes the stock of physical capital at the end of time $t$, with $K_{0}>0$, and $\beta$ is the discount factor, between zero and one.

The consumer takes fiscal policy and factor prices as given when deciding how to split her current income between consumption and savings. When the government finances its operations through income taxes, the Euler condition for the consumer is

$$
\frac{C_{t+1}}{C_{t}}=\beta\left[(1-\delta)+\left(1-\tau_{t+1}\right) r_{t+1}\right],
$$

while it is

$$
\frac{C_{t+1}}{C_{t}}=\beta\left[(1-\delta)+r_{t+1}\right]
$$

in the case of lump-sum taxation. Under both tax systems, the transversality condition is

$$
\lim _{t \rightarrow \infty} \beta^{t} K_{t+1} \frac{\partial U}{\partial C_{t}} \equiv \lim _{t \rightarrow \infty} \beta^{t} K_{t+1} \frac{1}{C_{t}}=0
$$

and $K_{t+1} \geq 0, C_{t} \geq 0$, for any period $t$. The Euler conditions and the transversality condition are jointly sufficient for consumer optimization.

\section{Equilibrium conditions and the balanced growth path}

\subsection{The competitive equilibrium}

A particular fiscal policy $\pi$ is characterized by a sequence of $\pi \equiv\left\{I_{t}^{g}, C_{t}^{g}, \tau_{t}, X_{t}\right\}_{t=0}^{\infty}$. Following Glomm and Ravikumar (1994), we define a $\pi$-competitive equilibrium $(\pi-C E)$ :

Definition 1 Given initial conditions $K_{0}, K_{0}^{g}>0$, a $\pi-C E$ for the overall economy is a set of allocations $\left\{C_{t}, K_{t+1}, K_{t+1}^{g}, I_{t}, L_{t}, Y_{t}\right\}_{t=0}^{\infty}$, a set of prices 
$\left\{r_{t}, w_{t}\right\}_{t=0}^{\infty}$ and a fiscal policy $\pi$, such that, given $\left\{r_{t}, w_{t}\right\}_{t=0}^{\infty}$ : (i) $\left\{L_{t}, K_{t+1}\right\}_{t=0}^{\infty}$ solve the profit maximizing problem of firms [i.e., (3)-(4) hold], (ii) $\left\{C_{t}, K_{t+1}\right\}_{t=0}^{\infty}$ maximize the utility of households [i.e., (19), $C_{t}, K_{t+1} \geq 0$ and either (15) and (17) under income taxes or (16) and (18) under lump-sum taxes hold], (iii) the public sector budget constraint [either (11) or (12)], together with (6), (9) and the technology constraints (2), (13), (7) hold and (iv) markets clear every period:

$$
\begin{aligned}
& L_{t}=1, \\
& Y_{t}=C_{t}+C_{t}^{g}+I_{t}+I_{t}^{g} .
\end{aligned}
$$

In fact, the condition that marginal utility at the origin is equal to infinity will guarantee that strict inequalities will hold for $K_{t+1}>0, C_{t}>0$ at all time periods, which we use in what follows.

\subsection{The balanced growth path}

The balanced growth path $(b g p)$ is a $\pi-C E$ trajectory along which aggregate variables grow at a zero or positive constant rate. Barro (1990), Rebelo (1991) and Jones and Manuelli (1997), among many others, have shown that Assumption 2 and the fact that $r_{t}$ must be constant and sufficiently high, are necessary and sufficient conditions for the equilibrium to display positive and steady growth in our Barro-type setting.

Under these conditions, it is easy to show from the equilibrium conditions that $Y_{t}, C_{t}, K_{t}, K_{t}^{g}, C_{t}^{g}$ and $X_{t}$ must all grow at the same constant rate, denoted $\bar{\gamma}$ hereinafter, along the bgp while bounded variables, such as $\tau_{t}$ and $r_{t}$, must remain constant. Therefore, the ratios $c_{t}=C_{t} / K_{t}, k_{t}^{g}=K_{t}^{g} / K_{t}$, $y_{t}=Y_{t} / K_{t}, c_{t}^{g}=C_{t}^{g} / K_{t}$ and $x_{t}=X_{t} / K_{t}$ are constant along the $b g p$.

In terms of these ratios, $\pi-C E$ conditions can be particularized for a $b g p$ equilibrium to the following system in $\bar{\gamma}, \bar{c}, \bar{k}^{g}, \bar{y}, \bar{r}, \bar{c}^{g}, \bar{x}$ and $\bar{\tau}$ (letters with bar refer to values along the $b g p)$ :

$$
\begin{aligned}
\bar{\gamma}+\delta & =\left(1-\varkappa_{i}-\varkappa_{c}\right) \bar{y}-\bar{c} \\
\bar{\gamma}+\delta^{g} & =\varkappa_{i} \bar{y}\left(\bar{k}^{g}\right)^{-1} \\
\bar{r} & =\alpha \bar{y} \\
\bar{y} & =A\left(\bar{k}^{g}\right)^{\theta} \\
\bar{c}^{g} & =\varkappa_{c} \bar{y}
\end{aligned}
$$


and either

$$
\begin{aligned}
\bar{x} & =0, \\
\bar{\tau} & =\varkappa_{i}+\varkappa_{c}, \\
1+\bar{\gamma} & =\beta[(1-\delta)+(1-\bar{\tau}) \bar{r}],
\end{aligned}
$$

under income taxes, or

$$
\begin{aligned}
\bar{\tau} & =0, \\
\bar{x} & =\left(\varkappa_{i}+\varkappa_{c}\right) \bar{y}, \\
1+\bar{\gamma} & =\beta(1-\delta+\bar{r}),
\end{aligned}
$$

under lump-sum taxes.

Condition (22) comes from the global constraint of resources, (23) is the public investment rule, (24) is the gross return on capital accumulation, (25) is the production function, (26) is the public consumption rule and, depending on the tax system considered, either (29) or (32) refer to the intertemporal substitution of consumption relationship and either (28) or (31) is the government budget constraint.

In parallel to Definition 1, for a particular stationary fiscal policy $\bar{\pi}=$ $\left\{\varkappa_{i}, \varkappa_{c}, \bar{\tau}, \bar{x}\right\}$, the $\bar{\pi}$-balanced growth path $(\bar{\pi}$-bgp $)$ is defined:

Definition $2 A \bar{\pi}$-bgp is a vector $\bar{\Pi}=\left\{\bar{\gamma}, \bar{c}, \bar{k}^{g}, \bar{y}, \bar{r}, \bar{c}^{g}\right\}$ and a stationary fiscal policy $\bar{\pi}$ satisfying: (22)-(26), either (27)-(29) under income taxes or (30)-(32) under lump-sum taxes, the transversality condition (19) and nonnegativity conditions $\bar{c}>0$ and $\bar{k}^{g}>0$.

The common growth rate property allows us to write the $b g p$ version of the transversality condition $(19)$ as, $\lim _{t \rightarrow \infty} \beta^{t}(1+\bar{\gamma}) \frac{1}{\bar{c}}=0$, which will be satisfied by any $\bar{\pi}$-bgp.

\subsection{The full depreciation $\bar{\pi}-b g p$}

Assumption 5: Both types of capital fully depreciate each period: $\delta=$ $\delta^{g}=1$.

Assumption 5 enables us to obtain an analytical characterization of the $\pi-C E$ and the $\bar{\pi}$-bgp allocations, so that our results can be easily compared 
with those obtained in previous research. ${ }^{10}$ Proposition 3 shows the existence of a single $\bar{\pi}$-bgp under $\delta=\delta^{g}=1,{ }^{11}$ provided that $\varkappa_{i}$ and $\varkappa_{c}$ are such that a positive amount of resources is left to the consumer every period. ${ }^{12}$

Proposition 3 If $\varkappa_{i}+\varkappa_{c}<1$, there is a single $\bar{\pi}$-bgp under income taxes. Under lump-sum taxes $\varkappa_{i}+\varkappa_{c}<1-\alpha \beta$ is required for a $\bar{\pi}$-bgp to exist. Then, the $\bar{\pi}$-bgp is also unique.

Proof. (i) Under income taxes, if $\varkappa_{i}+\varkappa_{c}<1$, the set of equations (22)(29), particularized to the case of full depreciation, has a single solution,

$$
\begin{gathered}
\bar{k}^{g d}=\frac{\varkappa_{i}}{\alpha \beta\left(1-\varkappa_{i}-\varkappa_{c}\right)}, \\
\bar{r}^{d}=A \alpha^{1-\theta}\left[\frac{\varkappa_{i}}{\beta\left(1-\varkappa_{i}-\varkappa_{c}\right)}\right]^{\theta}, \\
\bar{\gamma}^{d}=A \varkappa_{i}^{\theta}\left[\alpha \beta\left(1-\varkappa_{i}-\varkappa_{c}\right)\right]^{1-\theta}-1, \\
\bar{y}^{d}=A\left[\frac{\varkappa_{i}}{\alpha \beta\left(1-\varkappa_{i}-\varkappa_{c}\right)}\right]^{\theta}, \\
\bar{c}^{d}=\left(1-\varkappa_{i}-\varkappa_{c}\right)^{1-\theta}(1-\alpha \beta) A\left(\frac{\varkappa_{i}}{\alpha \beta}\right)^{\theta}, \\
\bar{c}^{g d}=\varkappa_{c} A\left[\frac{\varkappa_{i}}{\alpha \beta\left(1-\varkappa_{i}-\varkappa_{c}\right)}\right]^{\theta} .
\end{gathered}
$$

Since $\alpha \beta<1$, it is clear that $\bar{c}^{d}, \bar{k}^{g d}>0$, so the vector $\bar{\Pi}^{d}=\left\{\bar{\gamma}^{d}, \bar{c}^{d}, \bar{k}^{g d}, \bar{y}^{d}, \bar{r}^{d}, \bar{c}^{g d}\right\}$ defined by (33)-(38), will be a $\bar{\pi}-b g p$.

(ii) Similarly, under lump-sum taxes, combining (22)-(26) with (30)-(32) leads to,

$$
\bar{k}^{g n}=\frac{\varkappa_{i}}{\alpha \beta},
$$

\footnotetext{
${ }^{10}$ Together with the assumption that leisure does not enter in the utility function, which is of the logarithmic type. In section 4, full depreciation is shown not to be crucial for the conclusions relating to the growth-maximizing public expenditures policies, although it may be relevant for welfare analysis.

${ }^{11}$ In the Appendix (part 1), we show this statement for any $\delta, \delta^{g} \in[0,1]$.

${ }^{12}$ Hereinafter, a $d$-uppercase denotes a variable under distortionary taxation, while an $n$-uppercase denotes the value of the variable under non-distortionary taxes.
} 


$$
\begin{gathered}
\bar{r}^{n}=A \alpha^{1-\theta}\left(\frac{\varkappa_{i}}{\beta}\right)^{\theta}, \\
\bar{\gamma}^{n}=A \varkappa_{i}^{\theta}(\alpha \beta)^{1-\theta}-1, \\
\bar{y}^{n}=A\left(\frac{\varkappa_{i}}{\alpha \beta}\right)^{\theta}, \\
\bar{c}^{n}=A\left(\frac{\varkappa_{i}}{\alpha \beta}\right)^{\theta}\left[\left(1-\varkappa_{i}-\varkappa_{c}\right)-\alpha \beta\right], \\
\bar{c}^{g n}=\varkappa_{c} A\left(\frac{\varkappa_{i}}{\alpha \beta}\right)^{\theta} .
\end{gathered}
$$

Furthermore, $\bar{c}^{n}, \bar{k}^{g n}>0$ so long as $\varkappa_{i}+\varkappa_{c}<1-\alpha \beta$. Under that condition, the vector $\bar{\Pi}^{n}=\left\{\bar{\gamma}^{n}, \bar{c}^{n}, \bar{k}^{g n}, \bar{y}^{n}, \bar{c}^{g n}, \bar{r}^{n}\right\}$, which is uniquely defined by conditions (39)-(44) above, will be a $\bar{\pi}$-bgp

\subsection{Characterizing the full depreciation $\pi-C E$}

The simplicity of the model allows for the $\pi-C E$ to be analytically characterized. If we take a linear guess for the dependence of the decision rules for $C_{t}$ and $K_{t+1}$ on output: $C_{t}=a Y_{t}$ and $K_{t+1}=b Y_{t}$ to: (15), (17), (11), (6), (9), (3), together with $L_{t}=1$, we get under income taxes,

$$
\begin{aligned}
C_{t}^{d} & =\left[(1-\alpha \beta)\left(1-\varkappa_{i}-\varkappa_{c}\right)\right] A\left(K_{t}^{g d}\right)^{\theta}\left(K_{t}^{d}\right)^{1-\theta}, \quad t=0,1,2, \ldots,( \\
K_{t+1}^{d} & =\alpha \beta\left(1-\varkappa_{i}-\varkappa_{c}\right) A\left(K_{t}^{g d}\right)^{\theta}\left(K_{t}^{d}\right)^{1-\theta}, \quad t=0,1,2, \ldots
\end{aligned}
$$

while taking to (16), (18), (12), (6), (9) (3) the proposed linear rules for capital and consumption, together with $L_{t}=1$, we obtain under lump-sum taxes,

$$
\begin{aligned}
C_{t}^{n} & =\left[\left(1-\varkappa_{i}-\varkappa_{c}\right)-\alpha \beta\right] A\left(K_{t}^{g}\right)^{\theta}\left(K_{t}^{n}\right)^{1-\theta}, \quad t=0,1,2, \ldots, \\
K_{t+1}^{n} & =\alpha \beta A\left(K_{t}^{g n}\right)^{\theta}\left(K_{t}^{n}\right)^{1-\theta}, \quad t=0,1,2, \ldots
\end{aligned}
$$

Finally, under both tax systems, combining (2), (6) and $L_{t}=1$, we get

$$
K_{t+1}^{g}=\varkappa_{i} A\left(K_{t}^{g}\right)^{\theta} K_{t}^{1-\theta}, \quad t=0,1,2, \ldots
$$


which is, under either tax system, a set of three equations characterizing the law of motion for $C_{t}, K_{t+1}$ and $K_{t+1}^{g}$ along a $\pi$-CE. Indeed, we show in part 1 in the Appendix that, given $K_{0}, K_{0}^{g}>0$ and a fiscal policy $\pi$, the sequence $\left\{C_{t}^{d}, K_{t+1}^{d}\right\}_{t=0}^{\infty}$ under distorting taxes and the sequence $\left\{C_{t}^{n}, K_{t+1}^{n}\right\}_{t=0}^{\infty}$ under non-distorting taxes are the unique $\pi$-competitive equilibrium allocation. ${ }^{13}$

The dynamic properties of the model are basically those of the standard $A K$-model. In particular, the time evolution of $C_{t}, K_{t+1}$ and $K_{t+1}^{g}$, is characterized by the eigenvalue structure of the coefficient matrix of the state-space representation of the system above, in logs. Under either tax system, that representation is $\left[\hat{c}=\ln (C), \hat{k}=\ln (K), \hat{k}^{g}=\ln \left(K^{g}\right)\right]$,

$$
\begin{aligned}
\hat{c}_{t} & =d_{1}+\theta \hat{k}_{t}^{g}+(1-\theta) \hat{k}_{t}, \\
\left(\begin{array}{c}
\hat{k}_{t+1}^{g} \\
\hat{k}_{t+1}
\end{array}\right) & =\left(\begin{array}{l}
d_{2} \\
d_{3}
\end{array}\right)+\left(\begin{array}{cc}
\theta & 1-\theta \\
\theta & 1-\theta
\end{array}\right)\left(\begin{array}{l}
\hat{k}_{t}^{g} \\
\hat{k}_{t}
\end{array}\right),
\end{aligned}
$$

where $d_{1}, d_{2}$ and $d_{3}$ are constants. Independently of the tax system, this transition matrix has a zero eigenvalue and a second eigenvalue equal to one. The zero eigenvalue reflects the absence of transitional dynamics, while the unit eigenvalue is inherent to sustained growth models, ${ }^{14}$ implying that the ratios $K_{t}^{g} / K_{t}, C_{t} / K_{t}$ converge to constant levels, $\bar{k}^{g}$ and $\bar{c}$.

Since the competitive equilibrium is unique, given $K_{0}, K_{0}^{g}>0$ and a fiscal policy $\pi$, the previous system provides us with the values of $C_{0}, K_{1}$ and $K_{1}^{g}$ under either tax policy, the three variables growing from that time on at the common rate $\bar{\gamma}$ given by (35) and (41).

\section{Income versus lump-sum taxes}

In this section we discuss the possibility that the steady-state growth rate as well as the level of welfare might be higher under income than under lump-sum taxes when the government chooses the public investment/output ratio, $\varkappa_{i}$, to maximize either growth or welfare, respectively. The government is assumed to be constrained by the need to finance a fixed ratio of public consumption to output, $\varkappa_{c} \geq 0$ every period. From Proposition 3 , we already know that any $\varkappa_{c}<1$ is feasible under income taxes, while $\varkappa_{c}<1-\alpha \beta$ is

\footnotetext{
${ }^{13}$ The proof proceeds in a similar way to the argument in Glomm and Ravikumar $(1994,1999)$.

${ }^{14}$ See King and Rebelo (1988) and Caballé and Santos (1993).
} 
the feasibility condition under lump-sum taxes. Hence, we just consider parameterizations in

$$
\Omega \equiv\left\{\omega=\left(\varkappa_{c}, \alpha, \beta, \theta\right) \in \Re^{4}: \alpha, \beta, \theta \in(0,1), \alpha+\theta \leq 1, \varkappa_{c} \in[0,1-\alpha \beta)\right\} .
$$

\subsection{Maximizing steady-state growth}

In an economy without transitional dynamics, welfare is determined by the growth-rate and the initial consumption level, so the influence of the steadystate growth rate on welfare is obvious. We characterize in this section conditions under which a given tax system produces higher growth, leaving the discussion on the implied welfare levels for the next section. From (35), given a value of $\varkappa_{c}, \bar{\gamma}$ is strictly concave in $\varkappa_{i}$, with an interior maximum at

$$
\varkappa_{i}^{d *}=\theta\left(1-\varkappa_{c}\right),
$$

which gives us the growth-maximizing level ${ }^{15}$ of $\varkappa_{i}$ under income taxes. ${ }^{16}$ Condition (50) includes as special cases the result in section I in Barro (1990), Glomm and Ravikumar (1994) and Futagami et al. (1993), who obtain $\varkappa_{i}^{d *}=$ $\theta$ when working with $\varkappa_{c}=0$.

Under lump-sum taxes, (41) shows that the steady-state growth rate $\bar{\gamma}$ is monotonically increasing and concave in $\varkappa_{i}$, the level of $\varkappa_{i}$ being bounded from above by

$$
\varkappa_{i}^{n *}=1-\varkappa_{c}-\alpha \beta .
$$

This upper bound on $\varkappa_{i}$, which is inversely related to $\varkappa_{c}, \alpha$ and $\beta$, restricts the choice set of the government under lump-sum taxes.

Comparing (35) with (41), we see that the growth rate $\bar{\gamma}$ will be strictly higher under lump-sum than under income taxes for a common value of $\varkappa_{i}$, as shown in Figure 4.1. This is due to the disincentive effect that a positive capital tax rate exerts on the accumulation of private capital, relative to taxing lump-sum, when financing a given level of $\varkappa_{i}+\varkappa_{c}$. However, a government interested in maximizing long-run growth would choose a productive public investment ratio $\varkappa_{i}^{d *}$ under income taxes, choosing an investment ratio as close as possible to $\varkappa_{i}^{n *}$ under lump-sum taxes. As shown in Figure 4.1, $\varkappa_{i}^{d *}$ needs to be sufficiently higher than $\varkappa_{i}^{n *}$ for maximum long-run growth to be

\footnotetext{
${ }^{15}$ Along the paper, an asterisk denotes a value obtained under a growth-maximizing public investment strategy.

${ }^{16}$ Condition (50) is equivalent to that in section IV of Barro (1990).
} 
higher under distortionary taxation. But both optimal choices, $\varkappa_{i}^{d *}$ and $\varkappa_{i}^{n *}$ depend on the value of the exogenous ratio $\varkappa_{c}$, to which we turn now.

Plugging (50), (51) in (35), (41), the implied growth rates, denoted by $\bar{\gamma}^{d *}$ and $\bar{\gamma}^{n *}$, respectively, satisfy

$$
\bar{\gamma}^{d *}>\bar{\gamma}^{n *} \Leftrightarrow \Psi(\omega) \equiv 1-\frac{\beta \alpha}{\left(1-\varkappa_{c}\right)\left\{1-\theta\left[\left(1-\varkappa_{c}\right)(1-\theta)\right]^{\frac{1-\theta}{\theta}}\right\}}<0,
$$

with $\Psi(\omega)$ a function defined over $\Omega$. For any given values of $\alpha, \beta, \theta$ in $\Omega$, Proposition 4 guarantees the existence of a single and positive level of $\varkappa_{c}$, denoted by $\varkappa_{c}^{\gamma}$, for which $\Psi\left(\varkappa_{c}^{\gamma}, \alpha, \beta, \theta\right)=0$ and $\bar{\gamma}^{d *}=\bar{\gamma}^{n *}$. Values of $\varkappa_{c}$ above $\varkappa_{c}^{\gamma}$ will significantly reduce the government's choice set for $\varkappa_{i}$ under lump-sum taxes so that $\varkappa_{i}^{n *}$ will fall to the left of $A$ in Figure 4.1, making $\bar{\gamma}^{d *}$ to be higher than $\bar{\gamma}^{n *}{ }^{17}$ Above $\varkappa_{c}^{\gamma}$, the value of $\varkappa_{c}$ places an upper bound on the choice of productive public investment under lump-sum taxes, which is more damaging for growth than the distortion introduced by income taxes.

Finally, Corollary 5 shows that $\varkappa_{c}^{\gamma}$ is inversely related to $\alpha, \beta$ and $\theta$. Therefore, in a Barro-type setting, it is more likely that the maximum achievable growth rate will be higher under income than under lump-sum taxes in economies with high values of the unproductive public consumption/output ratio, high private and public capital productivity (high $\alpha$ and $\theta$ ) and where households weight heavily future consumption.

Proposition 4 There is a critical value of $\varkappa_{c}, 1-\frac{\alpha \beta}{1-\theta}<\varkappa_{c}^{\gamma}<1-\alpha \beta$, above (below) which the maximum achievable growth rate is higher (lower) under income than under lump-sum taxes.

Proof. From the expression of $\Psi(\omega)$ in (52), it is easy to check that: (a) $\Psi(\omega)$ is continuous on $\Omega ;(b)$ for any given values of $\alpha, \beta, \theta, \Psi\left(\varkappa_{c}=1-\frac{\alpha \beta}{1-\theta}, \alpha, \beta, \theta\right)=$ $1-\frac{1-\theta}{\left(1-\theta(\alpha \beta)^{\frac{1-\theta}{\theta}}\right)}>0$, while $\lim _{\varkappa_{c} \rightarrow(1-\alpha \beta)^{-}} \Psi(\omega)=1-\frac{1}{1-\theta[\alpha \beta(1-\theta)]^{\frac{1-\theta}{\theta}}}<0$; and (c) $\partial \Psi(\omega) / \partial \varkappa_{c}=-\beta \alpha \frac{1-\theta}{\left(1-\varkappa_{c}\right)^{2}} \frac{1-\left[\left(1-\varkappa_{c}\right)(1-\theta)\right]^{\frac{1-\theta}{\theta}}}{\left\{1-\theta\left[\left(1-\varkappa_{c}\right)(1-\theta)\right]^{\frac{1-\theta}{\theta}}\right\}}<0$ on $\Omega$. Therefore, there exists a single level of $\varkappa_{c}$ in $\left[1-\frac{\alpha \beta}{1-\theta}, 1-\alpha \beta\right), \varkappa_{c}^{\gamma}$, such that $\Psi(\omega)<0$ if and only if $\varkappa_{c}>\varkappa_{c}^{\gamma}$. From (52), that implies $\bar{\gamma}^{d *}>\bar{\gamma}^{n *}$, the opposite being true if $\varkappa_{c} \leq \varkappa_{c}^{\gamma}$

\footnotetext{
${ }^{17}$ In the non-congested Glomm-Ravikumar (1994) setup, where $\varkappa_{c}=0$, lump-sum taxes would always produce faster growth than income taxes, a special case of our result.
} 
Corollary $5 \varkappa_{c}^{\gamma}$ is inversely related to $\alpha, \theta$ and $\beta$.

Proof. $\Psi(\omega)=0$ defines an implicit function which is $\complement^{2}$ on $\Omega$. Let us denote $B=\left(1-\varkappa_{c}\right)\left\{1-\theta\left[\left(1-\varkappa_{c}\right)(1-\theta)\right]^{\frac{1-\theta}{\theta}}\right\}>0$. From Proposition 4, $\partial \Psi(\omega) / \partial \varkappa_{c}<0$. Consequently, by the implicit function theorem: $(a)$ $\frac{\partial \varkappa_{c}^{\gamma}}{\partial \alpha}=-\frac{\partial \Psi(\omega) / \partial \alpha}{\partial \Psi(\omega) / \partial \varkappa_{c}}<0$, since $\frac{\partial \Psi(\omega)}{\partial \alpha}=\frac{-\beta}{B}<0 ;$ (b) $\frac{\partial \varkappa_{c}^{\gamma}}{\partial \beta}=-\frac{\partial \Psi(\omega) / \partial \beta}{\partial \Psi(\omega) / \partial \varkappa_{c}}<$ 0 , since $\frac{\partial \Psi(\omega)}{\partial \beta}=\frac{-\alpha}{B}<0$; and $(c) \frac{\partial \varkappa_{c}^{\gamma}}{\partial \theta}=-\frac{\partial \Psi(\omega) / \partial \theta}{\partial \Psi(\omega) / \partial \varkappa_{c}}<0$, since $\frac{\partial \Psi(\omega)}{\partial \theta}=$ $\frac{\alpha \beta\left[\left(1-\varkappa_{c}\right)(1-\theta)\right]^{\frac{1-\theta}{\theta}} \ln \left[\left(1-\varkappa_{c}\right)(1-\theta)\right]}{\left(1-\varkappa_{c}\right) \theta\left\{1-\theta\left[\left(1-\varkappa_{c}\right)(1-\theta)\right]^{\frac{1-\theta}{\theta}}\right\}^{2}}$, which is negative because $\ln \left[\left(1-\varkappa_{c}\right)(1-\theta)\right]<$ 0

Since the economy displays no transition, at $t=1$ variables are already on their $b g p$, growing at the steady-state rate unless any policy or structural change occurs. Given $K_{0}, K_{0}^{g},(46),(48)$ and (49) show that state variables at $t=1$ under the growth-maximizing policies satisfy,

$$
\begin{aligned}
K_{1}^{d *} / K_{1}^{n *} & =\varkappa_{i}^{d *}+\varkappa_{c}=\theta+(1-\theta) \varkappa_{c}<1, \\
K_{1}^{g d *} / K_{1}^{g n *} & =\varkappa_{i}^{d *} / \varkappa_{i}^{n *}=\frac{\theta\left(1-\varkappa_{c}\right)}{1-\varkappa_{c}-\alpha \beta},
\end{aligned}
$$

so that the disincentive created by income taxes leads to a private capital stock below that accumulated under lump-sum taxes. The distortion on private capital accumulation decreases for high values of $\varkappa_{c}$, since the $K_{1}^{d *} / K_{1}^{n *}$ ratio depends positively on $\varkappa_{c}$. On the other hand, $K_{1}^{g d *} / K_{1}^{g n *}$ increases with $\varkappa_{c}$ and $K_{1}^{g d *}>K_{1}^{g n *}$ for $\varkappa_{c}>1-\frac{\alpha \beta}{1-\theta}$ (i.e., when $\varkappa_{i}^{d *}>\varkappa_{i}^{n *}$ ). The economy reacts to taxes on private capital with higher public capital accumulation, and this shift of resources from private to public capital accumulation can be enough to produce higher long-run growth.

The $K_{1}^{g d *} / K_{1}^{g n *}$-ratio increases with $\beta, \alpha$ and $\theta$ and, additionally, the $K_{1}^{d *} / K_{1}^{n *}$-ratio increases with $\theta$, which explains the result in Corollary 5 . The higher the output elasticities of either type of capital, $\alpha, \theta$, the lower will be the loss of future resources produced by distortionary taxation, so it will be more likely that this system produces higher growth.

Growth in this economy arises from the accumulation of both, private and public capital. A higher preference for future utility increases the desire to save more under non-distortionary taxation since then, the return to private capital is not taxed. Not leaving many resources for consumption, the government has a limit on their own productive investment expenditures, 
which restricts the possibilities for future growth. The distortion produced by public consumption in this model is reflected in the fact that, under lumpsum taxes, too much private capital is accumulated relative to public capital. This is negative for long-run growth, which explains the possible superiority of distortionary taxation.

Theoretical results in Proposition 4 are easy to show because both types of capital fully depreciate every period. However, full depreciation is not needed for the qualitative statements in this proposition. Maintaining the assumption of linear depreciation rates for both types of capital, it is shown in the Appendix (part 2): (a) there exists a single and well-defined bgp; $(b)$ the growth-maximizing public investment ratio under income taxes, $\varkappa_{i}^{d *}$, is given by $(50)$ for any $\delta, \delta^{g} ;(c)$ the result in Proposition 4 remains valid: the $\varkappa_{c}$-threshold, $\varkappa_{c}^{\gamma}$, for any $\delta^{g} \in[0,1]$ and $\delta=1$ is the same as with $\delta^{g}=\delta=1$, while it is higher ${ }^{18}$ than that value when $\delta \in[0,1)$.

\subsection{Maximizing welfare}

We now extend the analysis to discuss the possibility that the maximum level of welfare might be higher under income than under lump-sum taxes. Given $\varkappa_{c} \geq 0$ and $K_{0}, K_{0}^{g}>0$, we assume that the government chooses $\varkappa_{i}$ to maximize the welfare of the representative household over the set of $\pi$ $C E$ allocations. Since under full depreciation of both types of capital the economy displays no transition, the problem reduces to choosing $\varkappa_{i}$ such that,

$$
\max _{0 \leq \varkappa_{i} \leq 1} V\left(C_{0}, \bar{\gamma}\right)=\left[\frac{1}{1-\beta} \ln C_{0}+\frac{\beta}{(1-\beta)^{2}} \ln (1+\bar{\gamma})\right],
$$

subject to either (35) and (45) under income taxes or to (41) and (47) under lump-sum taxes. For $0<\beta<1, V\left(C_{0}, \bar{\gamma}\right)$ is strictly concave and bounded and the choice set is convex and compact, so that the optimization problem (53) has a single solution. Moreover, since $\lim _{\varkappa_{i} \rightarrow 0^{+}} V=\lim _{\varkappa_{i} \rightarrow 1^{-}} V=-\infty$, the welfare-maximizing level of $\varkappa_{i}$ falls strictly inside the interval $(0,1)$.

In fact, the welfare maximizing levels of $\varkappa_{i}$ under income taxes, $\varkappa_{i}^{d+}$, and

\footnotetext{
${ }^{18}$ So, for given $\beta, \alpha, \theta$, the range of $\varkappa_{c}$-values leading to higher growth under income taxes is smaller when private capital depreciation is not complete. A numerical example is also provided in table 6.2.1 in the Appendix (part 2), showing that, in fact, $\varkappa_{c}^{\gamma}$ varies very little for $\delta^{g}, \delta \in[0,1]$.
} 
under lump-sum taxes, $\varkappa_{i}^{n+}$, are given by: ${ }^{19}$

$$
\begin{gathered}
\varkappa_{i}^{d+}=\beta \theta\left(1-\varkappa_{c}\right)=\beta \varkappa_{i}^{d *}, \\
\varkappa_{i}^{n+}=\frac{\beta \theta}{1-\beta(1-\theta)}\left(1-\varkappa_{c}-\alpha \beta\right)=\frac{\beta \theta}{1-\beta(1-\theta)} \varkappa_{i}^{n *},
\end{gathered}
$$

with $\varkappa_{i}^{d *}$ and $\varkappa_{i}^{n *}$ being the growth-maximizing investment ratios defined in (50) and (51).

Since $\frac{\beta \theta}{1-\beta(1-\theta)}<1$, the growth-maximizing public investment/output ratio is strictly higher than the welfare-maximizing ratio under both tax rules, ${ }^{20}$ the difference between them being larger under the less distorting tax system. As in Glomm and Ravikumar (1994), under income taxes, the level of $\varkappa_{i}^{d+}$ differs from $\varkappa_{i}^{d *}$ by the factor $\beta$, since public investment only becomes productive next period, so the representative household discounts the positive effect of public investment on welfare by $\beta$. Under lump-sum taxes, the discrepancy between $\varkappa_{i}^{n *}$ and $\varkappa_{i}^{n+}$, measured by $\frac{\beta \theta}{1-\beta(1-\theta)}$, is smaller than $\beta$, but it increases with $\beta$ and $\theta$. The welfare-maximizing productive public investment ratio is higher under income than under lump-sum taxation for $\varkappa_{c}>\tilde{\varkappa}_{c}=1-\frac{\alpha}{1-\theta} \cdot{ }^{21}$

To discuss conditions under which welfare could be higher under income than under lump-sum taxes, we evaluate (53) under $\varkappa_{i}=\varkappa_{i}^{n+}$ and under $\varkappa_{i}=\varkappa_{i}^{d+}$, to obtain maximized levels of welfare $V^{n}$ and $V^{d}$, respectively. Their difference, $D=V^{n}-V^{d}$, can be written as ${ }^{22}$

$$
\begin{aligned}
(1-\beta) D(\omega)= & \ln \left(\frac{1-\beta}{1-\alpha \beta}\right)+\frac{1-\beta(1-\theta)}{1-\beta} \ln \left[\frac{1-\varkappa_{c}-\alpha \beta}{1-\beta(1-\theta)}\right] \\
& -\frac{1}{1-\beta} \ln \left(1-\varkappa_{c}\right)-\frac{1-\theta \beta}{1-\beta} \ln (1-\beta \theta),
\end{aligned}
$$

\footnotetext{
${ }^{19}$ See Appendix (part 3). Along the paper, a "+" uppercase denotes a value obtained under a welfare-maximizing public investment strategy.

${ }^{20} \varkappa_{i}^{d+}$ and $\varkappa_{i}^{d *}$ are equal to each other in the no-spillover model of Barro (1990), while $\varkappa_{i}^{d+}<\varkappa_{i}^{d *}$ in Futagami et al. (1993) and in Glomm and Ravikumar (1994).

${ }^{21}$ Since $\varkappa_{i}^{d+}>\varkappa_{i}^{n+}$ for $\varkappa_{c}>1-\frac{\alpha}{1-\theta}$, we will have equality between $\varkappa_{i}^{d+}$ and $\varkappa_{i}^{n+}$ when $\varkappa_{c}=0$ and $\alpha=1-\theta$ (i.e., no spillover in the productive process). Precisely under these conditions, Corsetti and Roubini (1996) show that the welfare-maximizing public investment ratio is independent of the tax system considered in a standard Barro-type framework.

${ }^{22}$ See Appendix (part 3) for more details on this point.
} 
where $D(\omega)$ is defined on $\Omega$.

Even though it is not possible to find explicit conditions implying $D(\omega)<$ 0 , for given values of $\alpha, \beta, \theta$, Proposition 8 guarantees existence of a single positive threshold $\varkappa_{c}^{v}$ for the non-productive investment ratio, above (below) which taxing the income of productive factors is welfare-superior (-inferior) to taxing lump-sum. Lemmas 6 and 7 show two intermediate results.

Lemma $6 D(0 ; \alpha, \beta, \theta)>0$ for any $\alpha, \beta, \theta$ in $\Omega$.

Proof. See Appendix (part 4)

Lemma 7 For any given values $\alpha_{0}, \beta_{0}, \theta_{0}$ in $(0,1)$ with $\alpha_{0}+\theta_{0} \leq 1$, the function $h\left(\varkappa_{c}\right)$ defined by $h\left(\varkappa_{c}\right)=D\left(\varkappa_{c}, \alpha_{0}, \beta_{0}, \theta_{0}\right)$ in (56) is concave, and has a single maximum at $\tilde{\varkappa}_{c}=1-\frac{\alpha_{0}}{1-\theta_{0}}$.

Proof. It is easy to see from (56) that, given $\alpha_{0}, \beta_{0}, \theta_{0}$ in $\Omega, h\left(\varkappa_{c}\right)$ is differentiable, the single solution to $\partial h / \partial \varkappa_{c}=\partial D\left(\varkappa_{c} ; \alpha_{0}, \beta_{0}, \theta_{0}\right) / \partial \varkappa_{c}=0$ is $\tilde{\varkappa}_{c}=1-\frac{\alpha_{0}}{1-\theta_{0}}$, and $\partial^{2} D\left(\varkappa_{c} ; \alpha_{0}, \beta_{0}, \theta_{0}\right) /\left.\partial \varkappa_{c}^{2}\right|_{\varkappa_{c}=\tilde{\varkappa}_{c}}<0$

Proposition 8 There is a critical value of $\varkappa_{c}$, $\varkappa_{c}^{v} \in\left(\tilde{\varkappa}_{c}, 1-\alpha \beta\right)$, so that income taxes are a preferred alternative to lump-sum taxes from the point of view of welfare if and only if $\varkappa_{c}>\varkappa_{c}^{v}$.

Proof. (a) $D(\omega)$, defined by (56) is continuous in $\Omega$; (b) we have seen in Lemma 6 that $D(0 ; \alpha, \beta, \theta)>0$ for any $\alpha, \beta, \theta$ in $\Omega$, while Lemma 7 shows that $\tilde{\varkappa}_{c}=\arg \max D\left(\varkappa_{c} ; \alpha, \beta, \theta\right)$, so that $D\left(\tilde{\varkappa}_{c} ; \alpha, \beta, \theta\right)>0 ;(c)$ at the highest feasible value of $\varkappa_{c}, \lim _{\varkappa_{c} \rightarrow(1-\alpha \beta)^{-}} D(\omega)=-\infty$. Therefore, there exists a single and well-defined threshold for $\varkappa_{c}, \varkappa_{c}^{v} \in\left(\tilde{\varkappa}_{c}, 1-\alpha \beta\right)$, such that $D(\omega)<0$ for any $\varkappa_{c}>\varkappa_{c}^{v}$

Corollary 9 shows that $\varkappa_{c}^{v}$ declines with $\alpha$, the output elasticity of private capital. We also show that there is a threshold $\theta^{*}$, such that $\varkappa_{c}^{v}$ declines with the output elasticity of public capital $\theta$, provided $\theta>\theta^{*}$. For standard parameterizations, the implied value of $\theta^{*}$ is low enough so that we can safely consider $\partial \varkappa_{c}^{v} / \partial \theta<0$. Finally, a numerical exploration shows that $\varkappa_{c}^{v}$ declines with $\beta$ when this parameter is close to one, as considered in standard calibrations. This should be expected, since (53) shows that as $\beta$ approaches 1 , maximizing long-run growth and maximizing welfare become equivalent. These results suggest that, as it was the case when comparing growth, high levels of $\beta, \alpha$ and $\theta$ increase the likelihood that taxing total income could be a welfare-superior alternative to taxing lump-sum. 
Corollary $9 \varkappa_{c}^{v}$ is inversely related to $\alpha$, while $\partial \varkappa_{c}^{v} / \partial \theta<0$ for $\theta \in\left(\max \left\{0, \theta^{*}\right\}, 1-\right.$ $\alpha]$, with $\theta^{*}=-\frac{\varkappa_{c}-\beta(1-\alpha)}{\beta\left(2-\varkappa_{c}-\alpha \beta\right)}$, and $\partial \varkappa_{c}^{v} / \partial \theta>0$ otherwise.

Proof. See Appendix (part 5)

Corollary 10 shows that $\varkappa_{i}^{d+}$ needs to be bigger than $\varkappa_{i}^{n+}$ for the maximum level of welfare to be higher under income than under lump-sum taxes, which is a condition similar to that found when comparing growth rates.

Corollary 10 A necessary condition for maximum welfare to be larger under income than under lump-sum taxes is that the welfare-maximizing public investment ratio be higher under income than under lump-sum taxes.

Proof. Let us assume that maximum welfare is larger under income than under lump-sum taxes. Then, by Proposition $8, \varkappa_{c}>\varkappa_{c}^{v}$. But $\varkappa_{c}^{v}>\tilde{\varkappa}_{c}$, so that $\varkappa_{c}>\tilde{\varkappa}_{c}$, which implies, from (54) and (55), $\varkappa_{i}^{d+}>\varkappa_{i}^{n+}$

Lack of transitional dynamics allows us to write welfare as in (53), a combination of initial consumption and long-term growth. In fact, in choosing one versus the other tax system, we are trading-off current versus future consumption. Taxing income from productive factors disincentives private capital accumulation and reduces long-run growth, with a moderate immediate consumption sacrifice. Alternatively, lump-sum taxation produces an important consumption sacrifice initially, to the possible benefit of higher long-term growth. From (45), (47), we have, under the welfare-maximizing public investment ratios,

$$
\frac{C_{0}^{d+}}{C_{0}^{n+}}=\frac{(1-\alpha \beta)\left(1-\varkappa_{c}\right)(1-\beta \theta)}{(1-\beta)\left(1-\varkappa_{c}-\alpha \beta\right)}[1-\beta(1-\theta)] .
$$

So far, we have analyzed the optimal choice for public investment under each of the two alternative tax systems, to then characterize optimal consumer decisions for each combination formed by a tax system and the associated optimal investment ratio. Condition (57) shows that initial consumption along the optimal path is in this economy always larger under income taxes than under lump-sum taxes. ${ }^{23}$ Moreover, that difference increases with $\varkappa_{c}$.

On the other hand, for small levels of the public consumption ratio $\varkappa_{c}$, growth is higher under non-distortionary taxes and there are two competing

\footnotetext{
${ }^{23}$ Which is easy to see when $\varkappa_{c}=0$. Since the ratio of initial consumptions is increasing in $\varkappa_{c}$, the general result follows.
} 
effects in (53). As we saw in the previous section, it is when $\varkappa_{c}$ increases that growth may become higher under distortionary taxation. Hence, any condition favoring higher growth under income taxes will also tend to induce that distortionary taxation might be preferred from the point of view of welfare. In fact, if growth ever gets higher under distortionary taxation, it is clear from (53) that this type of taxes will also be preferred in terms of welfare.

In particular, we have already seen that higher output elasticities of either type of capital attenuate the negative effects of the disincentive to accumulate capital, making more likely that long-run growth may be higher under distortionary than under non-distortionary taxation. It is therefore not surprising that they also favor that maximum welfare may be higher under distortionary taxation. Finally, maximizing welfare amounts to maximizing long-run growth for high values of $\beta$, so that an increase in the value of $\beta$ inside that range increases the likelihood that distortionary taxation may lead to a higher level of welfare.

\subsection{A numerical illustration}

We now illustrate the main findings from the previous sections with a simple numerical example. Specifically, for alternative calibrations (i.e., specific values for $\beta, \alpha$ and $\theta)$, we find the solutions to $D\left(\varkappa_{c} ; \beta, \alpha, \theta\right)=0$ and $\Psi\left(\varkappa_{c} ; \beta, \alpha, \theta\right)=0$. Assuming annual data, four alternative parameterizations (bench1, bench2, bench3 and bench4) are considered in table 4.1, all of them sharing a value $\beta=0.99$. In bench1, we assume a standard parametrization: $\alpha=0.4, \theta=0.15$ so that $\phi=1-\alpha-\theta=0.45$. Relative to bench1, bench2 is a small variation, with $\alpha=0.75$. This parameterization agrees with a broad interpretation of aggregate capital in the private producing process, $K_{t}$ that would include human and physical capital [see Romer (1987)]. In bench3 we consider the possibility of a technology intensive in productive public capital by setting $\theta=0.35$ [close to the value estimated in Aschauer (1989)], and $\alpha=0.4$, as in bench1. Finally, bench4 assumes a high productive technology in both types of capital, with $\alpha=0.7$ and $\theta=0.3$, implying absence of spillover effects.

For each parameterization considered in table 4.1, table 4.2 shows numerical values for: $(i)$ the two thresholds: $\varkappa_{c}^{\gamma}$ and $\varkappa_{c}^{v}$, the zeroes to $\Psi(\omega)$ and $D(\omega),(i i)$ for $\varkappa_{c}=\varkappa_{c}^{\gamma}$, the growth-maximizing public investment/output ratio under income taxes $\left[\varkappa_{i}^{d *}\right.$ from (50)] and the level of $\varkappa_{i}^{n *}$ under lump- 
sum taxes (51), and ( $i i i)$ for $\varkappa_{c}=\varkappa_{c}^{v}$, the welfare-maximizing public investment/output ratios under income taxes $\left[\varkappa_{i}^{d+}\right.$ in (54)] and under lump-sum taxes $\left[\varkappa_{i}^{n+}\right.$ from (55)].

As expected, both thresholds decrease when we increase $\alpha$ or $\theta$, although it seems that changes in the elasticity of private capital are more relevant. For instance, from bench1, the level of $\varkappa_{c}^{\gamma}$ decreases from $60.4 \%$ to $59.2 \%$ when $\theta$ increases from .15 to .35 , but it falls down to $24.9 \%$ when $\alpha$ is increased from .40 to .75 . A similar observation applies to $\varkappa_{c}^{v}$. The threshold above which growth is higher under distortionary taxation is always higher than the one above which distortionary taxation leads to higher welfare, so the latter situation arises more often, as we pointed out in the previous section.

Productive public investment ratios maximizing either growth or welfare under lump-sum taxes are well below those obtained under distortionary taxation. Finally, under either tax system, investment ratios maximizing welfare are very close to those maximizing long-run growth. Under distortionary taxation, the $\varkappa_{i}$-ratio maximizing welfare is always below that maximizing growth, the opposite result arising under lump-sum taxes. This is again due to the fact that initial consumption is higher under distortionary taxation.

The presence of the spillover externality allows us to change the values of the output elasticities of private and public capital, $\alpha$ and $\theta$, independently from each other, but that externality plays a minor role in the model. In fact, the proofs to all results in the previous section remain valid for the case $\phi=0$, so long as we maintain the restriction $\alpha+\theta=1$.

\section{Conclusions}

The superiority of non-distorting versus distorting taxation in endogenous growth economies has been challenged from different perspectives. In particular, it is already well known that positive taxation on the income of productive factors may be growth and welfare enhancing when it corrects a negative externality in the competitive equilibrium allocation.

Along this line, we have shown that the presence of a significant level of wasteful public expenditures is a sufficient condition for income taxes to lead to higher long-run growth and welfare than under lump-sum taxes. Specifically, we have characterized a threshold for the unproductive public expenditure/output ratio, above (below) which taxing productive factors' income results in a welfare-superior (inferior) financing alternative to taxing 
lump-sum. The higher the output elasticities of public and private capital, the lower the value of this threshold, favoring income taxes to be preferred to lump-sum taxes for steady-state growth and welfare.

A given ratio of public consumption to output plays the role of a negative externality, which is more damaging under non-distortionary taxation. In that case, accumulation of private capital is stronger because the return on capital is not being taxed. As a consequence, less resources are left for public investment, which limits the scope for future growth. A higher time discount factor increases the desire to accumulate capital, intensifying the effect of this externality and making more likely that distortionary taxes may be preferred to lump-sum taxes.

The more controversial assumption in our model is the existence of an exogenous path of public consumption that needs to be financed every period. Even though a first-best solution would set the level of this variable to zero every period, the reality is that it is significantly different from zero in actual economies, its ratio to GDP being rather stable over time in most cases. From a theoretical point of view, several assumptions could be made to justify a positive level of $C_{t}^{g} / Y_{t}$. The simplest and more standard choice is to assume that $C_{t}^{g}$ affects welfare in such a way that the marginal utility of public consumption becomes infinity when $C_{t}^{g}=0$ [for instance, considering a utility function $U\left(C_{t}, G_{t}^{g}\right)=\ln C_{t}+\varphi \ln C_{t}^{g}$, with $\varphi>0$ ]. Another possibility, more in line with our setup, is to consider that a minimum level of wasteful expenditures is required for the public sector to exist. Deviations above this minimum level, as explained by high administrative and bureaucratic costs, high levels of outstanding debt, existence of corruption costs, etc., would then characterize less efficient governments. We could then consider the minimum level of wasteful expenditures required to be endogenous to the government, investment in infrastructure or in learning government skills allowing for a reduction in this requirement on expenditures.

Welfare analysis has been relatively easy to make under the assumption that both types of capital fully depreciate every period. This assumption allows us to solve for the competitive equilibrium analytically, although in a framework too simple to establish strong policy recommendations. Regarding long-run growth, we have shown that full depreciation is not determinant for the qualitative and quantitative conclusions, since the analysis is of the steady-state type. Less than full depreciation in public and private capital would alter the model significantly, since the steady-state would no longer be reached in just one period. Welfare analysis then requires a full characteriza- 
tion of the transitional dynamics, which can only be done through numerical solution methods. That would be an interesting extension of this paper. 


\section{Appendix:}

\subsection{Part 1: Existence, uniqueness of equilibrium, and absence of transitional dynamics}

Our proof proceeds in a similar way to Glomm and Ravikumar $(1994,1999)$ : i) formulate an artificial planning problem; $i i)$ show the equivalence between that planning problem and the $\pi$-competitive equilibrium allocation; iii) show existence and uniqueness of a solution to the artificial planning problem; iv) show that a linear solution to the artificial planning problem exists; $v$ ) hence, conclude that the time path given by the linear solution is the single $\pi$-competitive equilibrium allocation. Once the linear solution to the $\pi$-competitive equilibrium allocation has been found, absence of transitional dynamics is already shown in the paper.

In our model, the second welfare theorem does not apply due to the distortions introduced by public capital and distortionary taxes. However, as in Glomm and Ravikumar $(1994,1999)$, we can formulate an artificial planning problem $[\mathrm{P}]$, whose solution can be shown to be a $\pi-C E$,

$$
\underset{\left\{C_{t}, K_{t+1}\right\}_{t=0}^{\infty}}{\operatorname{Max}} \sum_{t=0}^{\infty} \beta^{t} \ln \left(C_{t}\right)
$$

subject to

$$
C_{t}+C_{t}^{g}+K_{t+1}=\left(1-\tau_{t}\right) A L_{t}^{1-\alpha} K_{t}^{(\alpha+\phi+\theta)}\left(\frac{K_{t}^{g}}{K_{t}}\right)^{\theta}
$$

under distorting taxes or,

$$
C_{t}+C_{t}^{g}+K_{t+1}+X_{t}=A L_{t}^{1-\alpha} K_{t}^{(\alpha+\phi+\theta)}\left(\frac{K_{t}^{g}}{K_{t}}\right)^{\theta}
$$

under lump-sum taxes, given $K_{0}, K_{0}^{g}$ and a fiscal policy $\pi \equiv\left\{I_{t}^{g}, C_{t}^{g}, \tau_{t}, X_{t}\right\}_{t=0}^{\infty}$ at both cases.

For each possible $\pi$, we define the feasibility set:

$$
\Xi^{\pi d} \equiv\left[\left\{C_{t}, K_{t+1}\right\}_{t=0}^{\infty}: C_{t}, K_{t+1} \geq 0 ; C_{t}+C_{t}^{g}+K_{t+1} \leq\left(1-\tau_{t}\right) Y_{t} ; K_{0}, K_{0}^{g}>0\right]
$$


under distorting taxes and

$\Xi^{\pi n} \equiv\left[\left\{C_{t}, K_{t+1}\right\}_{t=0}^{\infty}: C_{t}, K_{t+1} \geq 0 ; C_{t}+C_{t}^{g}+K_{t+1}+X_{t} \leq Y_{t} ; K_{0}, K_{0}^{g}>0\right]$,

under non-distorting taxes. These are the $\pi$-feasible allocation sets under each tax system.

Proposition 11 . Equivalence: Given $K_{0}$ and $K_{0}^{g}$ and a fiscal policy $\pi$, the allocation $\left\{C_{t}, K_{t+1}\right\}_{t=0}^{\infty}$ solves problem [P] if and only if it is part of a $\pi$-competitive equilibrium allocation.

Proof. Since the private sector is not allowed to borrow or lend and the production function shows constant return to scale (i.e., profits are zero), it is straightforward to see the equivalence between the optimally conditions for problem $[P]$ and conditions characterizing the $\pi$-competitive equilibrium [Proposition 1 in Section 3 in Glomm and Ravikumar (1994)]

Proposition 12 . Existence and Uniqueness: Given $K_{0}$ and $K_{0}^{g}$ and a fiscal policy $\pi$, there exists a unique sequence $\left\{C_{t}, K_{t+1}\right\}_{t=0}^{\infty}$ that solves problem $[P]$.

Proof. Our proof of existence proceeds in three steps.

i) from (10), the sequence $\left\{K_{t}^{g}\right\}_{t=0}^{\infty}$ is bounded above by $\mu^{t} K_{0}^{g}$, with $\mu=$ $1+\bar{\gamma}$. As a consequence, $\sum_{t=0}^{\infty} \beta^{t} \ln \left(C_{t}\right)$ is bounded above for all feasible consumption paths. To prove that, feasibility implies:

$$
\begin{aligned}
C_{t} & \leq Y_{t} \leq A K_{t}^{(\alpha+\phi)}\left(K_{t}^{g}\right)^{\theta} \leq A K_{t}^{(\alpha+\phi)}\left(\mu^{t} K_{0}^{g}\right)^{\theta}, \\
K_{t+1} & \leq Y_{t} \leq A K_{t}^{(\alpha+\phi)}\left(K_{t}^{g}\right)^{\theta} \leq A K_{t}^{(\alpha+\phi)}\left(\mu^{t} K_{0}^{g}\right)^{\theta} .
\end{aligned}
$$

We define $H_{t}=A\left(\mu^{t} K_{0}^{g}\right)^{\theta}$. From the second inequality it follows that:

$$
K_{t+1} \leq \max \left\{H_{t}^{1 /(1-\alpha-\phi)}, K_{t}\right\} \text {, for all } t,
$$

since $\alpha+\phi \in(0,1)$. That condition means that the growth rate of $K_{t}$ is bounded above by the growth rate of $H_{t}^{1 /(1-\alpha-\phi)}$, that is

$$
K_{t} \leq K_{0} \mu^{t \theta /(1-\alpha-\phi)} \text { for all } t .
$$

Therefore,

$$
\sum_{t=0}^{\infty} \beta^{t} \ln \left(C_{t}\right) \leq \ln \left[A\left(K_{0}^{g}\right)^{\theta}\right] \sum_{t=0}^{\infty} \beta^{t}+\theta \ln (\mu) \sum_{t=0}^{\infty} t \beta^{t}+(\alpha+\phi) \sum_{t=0}^{\infty} \beta^{t} \ln K_{t} .
$$


The first two terms at the right hand side are clearly finite and the third is also bounded above because

$$
\sum_{t=0}^{\infty} \beta^{t} \ln K_{t} \leq \ln \left(K_{0}\right) \sum_{t=0}^{\infty} \beta^{t}+\frac{\theta}{(1-\alpha-\phi)} \ln (\mu) \sum_{t=0}^{\infty} t \beta^{t}
$$

is finite.

ii) by the Lebesgue Dominated Convergence theorem, the objective function in problem $[P]$ is continuous on the set of $\pi$-feasible allocations.

iii) by Tychonoff's theorem, the feasibility sets $\Xi^{\text {rd }}$ and $\Xi^{\pi n}$ are compact.

Thus, from i)-iii) we can apply the maximum principle, which ensures the existence of at least one solution to problem $[P]$.

Uniqueness follows from concavity of the utility function together with the convexity of $\Xi^{\pi d}$ and $\Xi^{\pi n}$

Proposition 13 The sequence $\left\{C_{t}^{d}, K_{t+1}^{d}\right\}_{t=0}^{\infty}$ given by the linear system (45) and (46) is a $\pi$-competitive equilibrium allocation under distorting taxes.

Proof. In competitive equilibrium $C_{t}, K_{t+1}$ and $K_{t+1}^{g}$ must be strictly greater than zero. We make a guess that $C_{t}$ and $K_{t+1}$ are linear on current output: $C_{t}=a Y_{t}$ and $K_{t+1}=b Y_{t}$. Combining these guesses with (17) and (3)

$$
\frac{a b^{1-\theta} \varkappa_{i}^{\theta} Y_{t}}{a Y_{t}}=\beta\left(1-\tau_{t+1}\right) \alpha A\left(\frac{\varkappa_{i} Y_{t}}{b Y_{t}}\right)^{\theta},
$$

where we have considered that, from (2),

$$
Y_{t+1}=A K_{t+1}^{1-\theta}\left(K_{t+1}^{g}\right)^{\theta}=A b^{1-\theta} \varkappa_{i}^{\theta} Y_{t}
$$

since $\alpha+\theta+\phi=1$. Manipulating (63),

$$
b^{1-\theta} \varkappa_{i}^{\theta}=\beta\left(1-\tau_{t+1}\right) \alpha\left(\frac{\varkappa_{i}}{b}\right)^{\theta} \Leftrightarrow b=\alpha \beta\left(1-\tau_{t+1}\right) .
$$

Finally, combining the previous guesses with (21) and the fact that $I_{t}^{g}=\varkappa_{i} Y_{t}$ and $C_{t}^{g}=\varkappa_{c} Y_{t}$, we get

$$
Y_{t}\left(b+a+\varkappa_{i}+\varkappa_{c}\right)=Y_{t} \Leftrightarrow a=\left(1-\varkappa_{i}-\varkappa_{c}\right)-\alpha \beta\left(1-\tau_{t+1}\right) .
$$


Proposition 14 The sequence $\left\{C_{t}^{n}, K_{t+1}^{n}\right\}_{t=0}^{\infty}$ given by the linear system (47) and (48) is a $\pi$-competitive equilibrium allocation under non-distorting taxes.

Proof. The proof is equivalent to the previous one but using the equilibrium conditions under non-distorting taxes

Finally, from the Equivalence Proposition 11 above, we conclude that the sequence $\left\{C_{t}, K_{t+1}\right\}_{t=0}^{\infty}$, given by the linear systems in Propositions 13 and 14 , is the unique $\pi$-competitive equilibrium allocation under each alternative tax system.

\subsection{Part 2: Partial depreciation of capital stocks}

Conditions (29) and (32) can be jointly written,

$$
\bar{\gamma}=\beta[(1-\delta)+(1-\bar{\tau}) \bar{r}]-1,
$$

with $\bar{\tau}=0$ under lump-sum taxes and $\bar{\tau}=\varkappa_{i}+\varkappa_{c}$ under income taxes.

Using this together with (22)-(25), which are valid under either tax system, we get,

$$
\Phi\left(\bar{k}^{g}\right)=A\left(\bar{k}^{g}\right)^{\theta-1}\left(\varkappa_{i}-\beta \alpha(1-\bar{\tau}) \bar{k}^{g}\right)+1-\delta^{g}-\beta(1-\delta)=0,
$$

whose positive roots are potential candidates to be steady-state values of $\bar{k}^{g}$. Since $\Phi\left(\bar{k}^{g}\right)$ is continuous and decreasing in $\bar{k}^{g}$, with $\lim _{\bar{k}^{g} \rightarrow 0^{+}} \Phi\left(\bar{k}^{g}\right)=+\infty$ and $\lim _{\bar{k}^{g} \rightarrow+\infty} \Phi\left(\bar{k}^{g}\right)=-\infty$, there exists a single $\bar{k}^{g}>0$ such that $\Phi\left(\bar{k}^{g}\right)=0$, which defines the steady-state of the economy.

Lemma 15 Under either tax system, the steady-state level of $\bar{k}^{g}$ is directly related to the productive public investment ratio $\varkappa_{i}$.

Proof. Applying the implicit function theorem to the $\complement^{2}-$ mapping $\Phi(\cdot)$ and using the fact that under income taxes $\bar{\tau}=\varkappa_{i}+\varkappa_{c}$, we get,

$$
\frac{\partial \bar{k}^{g d}}{\partial \varkappa_{i}}=-\frac{\partial \Phi\left(\bar{k}^{g d}\right) / \partial \varkappa_{i}}{\partial \Phi\left(\bar{k}^{g d}\right) / \partial \bar{k}^{g d}}=\frac{1+\beta \alpha \bar{k}^{g d}}{(1-\theta) \frac{1}{\bar{k}^{g d}} \varkappa_{i}+\alpha \beta \theta\left(1-\varkappa_{i}-\varkappa_{c}\right)}>0,
$$

while under lump-sum taxes,

$$
\frac{\partial \bar{k}^{g n}}{\partial \varkappa_{i}}=-\frac{\partial \Phi\left(\bar{k}^{g n}\right) / \partial \varkappa_{i}}{\partial \Phi\left(\bar{k}^{g n}\right) / \partial \bar{k}^{g n}}=\frac{1}{(1-\theta) \frac{1}{k^{g n}} \varkappa_{i}+\alpha \beta \theta}>0 .
$$


Lemma 16 Under income taxes, the growth-maximizing ratio is $\varkappa_{i}^{d *}=\theta(1-$ $\left.\varkappa_{c}\right)$ for any $\delta, \delta^{g} \in[0,1]$.

Proof. From (23) and (22) we get: $\lim _{\varkappa_{i} \rightarrow 0} \bar{\gamma}=-\delta^{g}<0$ and $\lim _{\varkappa_{i} \rightarrow 1^{-}} \bar{\gamma}=$ $-\varkappa_{c} A\left(\bar{k}^{g d}\right)^{\theta}-\bar{c}-\delta<0$, so that positive values of $\bar{\gamma}$ can be attained only for values of $\varkappa_{i}^{d *}$ in the open interval $(0,1)$. Taking derivatives in (23) and combining

$$
\frac{\partial \bar{\gamma}}{\partial \varkappa_{i}}=A\left(\bar{k}^{g d}\right)^{\theta-2}\left(\bar{k}^{g d}-\varkappa_{i}(1-\theta) \frac{\partial \bar{k}^{g d}}{\partial \varkappa_{i}}\right)=0,
$$

with (69) implies $\varkappa_{i}^{d *}=\theta\left(1-\varkappa_{c}\right)$ for any $\delta$ and $\delta^{g}$

The qualitative result in Proposition 4 holds for $\delta^{g}<1$. The $\varkappa_{c}^{\gamma}$-threshold is the same as that characterized in the proposition, so long as $\delta=1$. If $\delta<1$, the $\varkappa_{c}^{\gamma}$-threshold is higher than that in Proposition 4.

Lemma 17 There is a critical value of $\varkappa_{c}$, $\hat{\varkappa}_{c}^{\gamma}$, above (below) which the maximum achievable growth rate is higher (lower) under income than under lump-sum taxes. For any $\delta^{g} \in[0,1]$ and $\delta=1$, this $\varkappa_{c}$-threshold is the same as with $\delta^{g}=\delta=1$, while it is higher than that value when $\delta \in[0,1)$.

Proof. Since the growth rate under lump-sum taxes is increasing in $\varkappa_{i}$ for any $\delta^{g}, \delta \in[0,1]$, the highest feasible growth rate that can be achieved under lump-sum taxes is again obtained for a productive investment ratio of $\varkappa_{i}^{n *}$, the level of $\varkappa_{i}$ implying $\bar{c}^{n}=0$. Let us denote by $\hat{\varkappa}_{c}^{\gamma}$ the $\varkappa_{c}$-threshold above which the maximum growth rate under income taxes becomes higher than growth under $\varkappa_{i}^{n *}$, and by $\bar{k}^{g d *}, \bar{k}^{g n *}$, the steady-state values of the $\bar{K}_{t}^{g} / \bar{K}_{t}$ ratio obtained under $\varkappa_{i}^{d *}, \varkappa_{i}^{n *}$, the growth maximizing investment policies under income and lump-sum taxes, respectively, when $\varkappa_{c}=\hat{\varkappa}_{c}^{\gamma}$

Thus, by definition, $\hat{\varkappa}_{c}^{\gamma}, \varkappa_{i}^{n *}, \bar{k}^{g d *}$ and $\bar{k}^{g n *}$ must verify: (1) $\Phi\left(\bar{k}^{g d *}\right)=0$ under income taxes for $\varkappa_{i}=\varkappa_{i}^{d *},(2) \Phi\left(\bar{k}^{g n *}\right)=0$ under lump-sum taxes for $\varkappa_{i}=\varkappa_{i}^{n *}$, (3) $\bar{c}^{n}=0$ under lump-sum taxes for $\varkappa_{i}=\varkappa_{i}^{n *}$, and (4) for $\varkappa_{c}=\hat{\varkappa}_{c}^{\gamma}$, the growth rate obtained under $\varkappa_{i}^{d *}$, must be equal to the upper bound on growth rates under lump-sum taxes, i.e., the growth rate that would be obtained under $\varkappa_{i}^{n *}$.

These conditions reduce to:

$$
\begin{gathered}
A\left(\bar{k}^{g d *}\right)^{\theta-1}\left(1-\hat{\varkappa}_{c}^{\gamma}\right)\left[\theta-\beta \alpha(1-\theta) \bar{k}^{g d *}\right]+1-\delta^{g}-\beta(1-\delta)=0, \\
A\left(\bar{k}^{g n *}\right)^{\theta-1}\left(\varkappa_{i}^{n *}-\beta \alpha \bar{k}^{g n *}\right)+1-\delta^{g}-\beta(1-\delta)=0,
\end{gathered}
$$




$$
\begin{gathered}
\left(1-\varkappa_{i}^{n *}-\hat{\varkappa}_{c}^{\gamma}\right) A\left(\bar{k}^{g n *}\right)^{\theta}-\varkappa_{i}^{n *} A\left(\bar{k}^{g n *}\right)^{\theta-1}-\delta+\delta^{g}=0, \\
\varkappa_{i}^{n *}=\theta\left(1-\hat{\varkappa}_{c}^{\gamma}\right)\left(\frac{\bar{k}^{g n *}}{\bar{k}^{g d *}}\right)^{1-\theta} .
\end{gathered}
$$

Subtracting (72) from (73) and combining with (74),

$$
\frac{\bar{k}^{g n *}}{\bar{k}^{g d *}}=\left[(1-\theta)\left(1-\hat{\varkappa}_{c}^{\gamma}\right)\right]^{1 / \theta} .
$$

Plugging (76) into (75),

$$
\varkappa_{i}^{n *}=\theta(1-\theta)^{\frac{1-\theta}{\theta}}\left(1-\hat{\varkappa}_{c}^{\gamma}\right)^{\frac{1}{\theta}} .
$$

On the other hand, adding up (73) and (74),

$$
A\left(\bar{k}^{g n *}\right)^{\theta}\left(1-\varkappa_{i}^{n *}-\hat{\varkappa}_{c}^{\gamma}-\beta \alpha\right)+(1-\beta)(1-\delta)=0 .
$$

If $\delta=1$ then, for any $\delta^{g} \in[0,1]$, we have from (78): $\varkappa_{i}^{n *}=1-\hat{\varkappa}_{c}^{\gamma}-\beta \alpha$, since $\bar{k}^{g n *}>0$, and plugging (77) into this relationship, we obtain,

$$
\hat{\varkappa}_{c}^{\gamma}-1+\frac{\beta \alpha}{1-\theta\left[\left(1-\hat{\varkappa}_{c}^{\gamma}\right)(1-\theta)\right]^{\frac{1-\theta}{\theta}}}=0,
$$

which has the same roots as the $\Psi$-function defined in (52). Consequently, $\hat{\varkappa}_{c}^{\gamma}=\varkappa_{c}^{\gamma}$, the same value obtained under full depreciation of both types of capital. Alternatively, if $\delta \in[0,1)$ we would have $(1-\beta)(1-\delta)>0$ in (78), which implies that, for any $\delta^{g} \in[0,1]$, we have $\varkappa_{i}^{n}>1-\hat{\varkappa}_{c}^{\gamma}-\beta \alpha$, and hence $\hat{\varkappa}_{c}^{\gamma}>\varkappa_{c}^{\gamma}$

Even though the $\varkappa_{c}^{\gamma}$-threshold changes with the depreciation rate of private capital, this effect is minor. Table 6.2 summarizes a numerical example for $\theta=.15, \alpha=.75$ and $\beta=.99$. System (72)-(75) is solved for this calibration to obtain $\hat{\varkappa}_{c}^{\gamma}$, which turns out to vary just between $24.9 \%$ and $25.5 \%$ for $\delta^{g}, \delta^{k} \in[0,1]$.

\subsection{Part 3: The welfare-maximizing public investment ratio}

Proof. Under income taxes: plugging (45) and (35) into (53), we get the optimization problem,

$$
\max _{0 \leq \varkappa_{i} \leq 1} \frac{1}{1-\beta}\left(\begin{array}{c}
\ln \left[\left(1-\varkappa_{i}-\varkappa_{c}\right)(1-\alpha \beta)\right]+ \\
+\frac{\beta}{(1-\beta)} \theta\left[\ln \varkappa_{i}+(1-\theta) \ln \left(1-\varkappa_{i}-\varkappa_{c}\right)\right]+\Delta
\end{array}\right),
$$


where $\Delta=\frac{\beta}{1-\beta} \ln A+\frac{\beta}{1-\beta}(1-\theta) \ln (\alpha \beta)+\ln \left(A\left(K_{0}^{g}\right)^{\theta} K_{0}^{1-\theta}\right)$. Hence, the welfare-maximizing ratio, $\varkappa_{i}^{d+}$, is the solution to,

$$
\frac{-1}{1-\varkappa_{i}^{d+}-\varkappa_{c}}+\frac{\beta}{1-\beta}\left(\frac{\theta}{\varkappa_{i}^{d+}}-(1-\theta) \frac{1}{1-\varkappa_{i}^{d+}-\varkappa_{c}}\right)=0,
$$

leading to: $\varkappa_{i}^{d+}=\beta \theta\left(1-\varkappa_{c}\right)$.

In a similar way, under lump-sum taxes: plugging (47) and (41) into (53),

$$
\max _{0 \leq \varkappa_{i} \leq 1} \frac{1}{1-\beta}\left(\ln \left[\left(1-\varkappa_{i}-\varkappa_{c}\right)-\alpha \beta\right]+\frac{\beta}{(1-\beta)} \theta \ln \varkappa_{i}+\Delta\right),
$$

and the welfare-maximizing ratio, $\varkappa_{i}^{n+}$, the solution to

$$
\frac{-1}{1-\varkappa_{i}^{n+}-\varkappa_{c}-\alpha \beta}+\frac{\beta}{1-\beta} \theta \frac{1}{\varkappa_{i}^{n+}}=0
$$

is: $\varkappa_{i}^{n+}=\frac{\beta \theta}{1-\beta(1-\theta)}\left(1-\varkappa_{c}-\alpha \beta\right)$.

Given $K_{0}^{g}, K_{0}>0$ as initial conditions, to obtain a closed form for the welfare function under income taxes, we evaluate (53) under $\varkappa_{i}=\varkappa_{i}^{d+}$ and $\bar{\tau}=\varkappa_{c}+\varkappa_{i}^{d+}$, obtaining $V^{d}$ :

$$
\begin{array}{r}
V^{d}=\left[\frac{1}{1-\beta} \ln C_{0}^{d+}+\frac{\beta}{(1-\beta)^{2}} \ln \left(1+\bar{\gamma}^{d+}\right)\right], \text { with } \\
C_{0}^{d+}=\left(1-\varkappa_{c}\right)(1-\beta \theta)(1-\alpha \beta) Y_{0}, \\
1+\bar{\gamma}^{d+}=A\left(1-\varkappa_{c}\right)(\beta \theta)^{\theta}[\alpha \beta(1-\beta \theta)]^{1-\theta},
\end{array}
$$

so that,

$$
\begin{aligned}
(1-\beta) V^{d}= & \ln \left(1-\varkappa_{c}\right)+\ln (1-\beta \theta)+\ln (1-\alpha \beta)+\ln Y_{0}+ \\
& +\frac{\beta}{(1-\beta)}\left\{\begin{array}{c}
\ln A+\ln \left(1-\varkappa_{c}\right)+\theta \ln (\beta \theta)+ \\
+(1-\theta)[\ln (\alpha \beta)+\ln (1-\beta \theta)]
\end{array}\right\} .
\end{aligned}
$$

Under lump-sum taxes, we evaluate (53) under $\varkappa_{i}=\varkappa_{i}^{n+}$ and $\bar{\tau}=0$, obtaining $V^{n}$ :

$$
\begin{array}{r}
V^{n}=\left[\frac{1}{1-\beta} \ln C_{0}^{n+}+\frac{\beta}{(1-\beta)^{2}} \ln \left(1+\bar{\gamma}^{n+}\right)\right], \text { with } \\
C_{0}^{n+}=\frac{(1-\beta)\left(1-\varkappa_{c}-\alpha \beta\right)}{1-\beta(1-\theta)} Y_{0}, \\
1+\bar{\gamma}^{n+}=A\left[\frac{\beta \theta}{1-\beta(1-\theta)}\left(1-\varkappa_{c}-\alpha \beta\right)\right]^{\theta}(\alpha \beta)^{1-\theta},
\end{array}
$$


so that,

$$
\begin{aligned}
& \quad(1-\beta) V^{n}=\ln (1-\beta)+\ln \left(1-\varkappa_{c}-\alpha \beta\right)-\ln (1-\beta(1-\theta))+\ln Y_{0}+(89) \\
& +\frac{\beta}{(1-\beta)}\left\{\begin{array}{c}
\ln A+\theta\left[\ln (\beta \theta)+\ln \left(1-\varkappa_{c}-\alpha \beta\right)-\ln (1-\beta(1-\theta))\right]+ \\
+(1-\theta) \ln (\alpha \beta)
\end{array}\right\} .
\end{aligned}
$$

Finally, from (86) and (89), it is easy to show that $(1-\beta)\left(V^{n}-V^{d}\right)$ is given by $(56)$

\subsection{Part 4: Proof of Lemma 6}

Proof. From (56), we have $\frac{\partial D(0 ; \alpha, \beta, \theta)}{\partial \alpha}=-\beta \frac{\theta \beta}{(1-\alpha \beta)(1-\beta)}<0$ at $\varkappa_{c}=$ 0 . It suffices to show that for the highest feasible value of $\alpha, \alpha=1-\theta$, $D(0 ; 1-\theta, \beta, \theta)=\ln \left(\frac{1-\beta}{1-(1-\theta) \beta}\right)-\frac{1-\theta \beta}{1-\beta} \ln (1-\beta \theta)>0$, to conclude that $D(0 ; \alpha, \beta, \theta)>0$ for any $\alpha, \beta, \theta$ in $\Omega$.

To show that $D(0 ; 1-\theta, \beta, \theta)>0$, let us denote by

$$
f(\theta ; \beta)=\ln (1-\beta)-\ln [1-\beta(1-\theta)] ; g(\theta ; \beta)=\frac{1-\beta \theta}{1-\beta} \ln (1-\theta \beta) .
$$

We want to show that $w(\theta ; \beta) \equiv f(\theta ; \beta)-g(\theta ; \beta)>0$.

Second derivatives are:

$$
\frac{\partial^{2} f}{\partial \theta^{2}}=\frac{\beta^{2}}{[1-\beta(1-\theta)]^{2}} ; \frac{\partial^{2} g}{\partial \theta^{2}}=\frac{\beta^{2}}{(1-\beta)(1-\beta \theta)},
$$

so that

$$
\frac{\partial^{2} w}{\partial \theta^{2}}=\beta^{2} \frac{(1-\beta)(1-\beta \theta)-[1-\beta(1-\theta)]^{2}}{[1-\beta(1-\theta)]^{2}(1-\beta)(1-\beta \theta)} .
$$

Since $0<\beta<1$ and $0<\theta<1$, we have:

$$
\begin{aligned}
\operatorname{sgn}\left(\frac{\partial^{2} w}{\partial \theta^{2}}\right) & =\operatorname{sgn}\left[(1-\beta)(1-\beta \theta)-[1-\beta(1-\theta)]^{2}\right]= \\
& =\operatorname{sgn}\left[-\beta \theta^{2}-3(1-\beta) \theta+(1-\beta)\right] .
\end{aligned}
$$

Let us denote: $\varphi(\theta ; \beta)=\beta \theta^{2}+3(1-\beta) \theta-(1-\beta)$, a second degree polynomial in $\theta$ for each given $\beta$, with $\varphi(0 ; \beta)<0, \varphi(1 ; \beta)>0$. Its two roots are given by:

$$
\theta_{\beta}=\frac{-3(1-\beta) \pm \sqrt{9(1-\beta)^{2}+4 \beta(1-\beta)}}{2 \beta},
$$


where it is clear that $\theta_{\beta}^{-}<0$, while it is not hard to show that $\theta_{\beta}^{+}<1$.

Hence, in the range of feasible values of $\theta$, the $[0,1]$-interval, the $\varphi(\theta ; \beta)$ polynomial moves from negative to positive, crossing the $\theta$-axis just once. Equivalently, $w(\theta ; \beta)$ is convex between $\theta=0$ and the positive root, $\theta=\theta_{\beta}^{+}$, and concave to the right of that point, being differentiable on $[0,1]$. Together with $w(0 ; \beta)=0, w(1 ; \beta)=0, w^{\prime}(0 ; \beta)=0$ and $w^{\prime}(1 ; \beta)<0$, all these conditions imply that $w(\theta ; \beta)$ reaches a single local maximum between $\theta_{\beta}^{+}$ and $\theta=1$, taking always positive values on the interval $[0,1]$

\subsection{Part 5: Proof of Corollary 9}

Proof. $D(\omega)$ in (56) defines an implicit function in $\omega$. Since $D(\omega) \in \complement^{2}$ on its domain, $\Omega$, the implicit function theorem applies. In addition, we know from Lemma 7 that $\partial D(\omega) / \partial \varkappa_{c}<0$ for $\varkappa_{c} \geq \varkappa_{c}^{v}$. Hence:

$$
\begin{aligned}
\text { (a) } \partial \varkappa_{c}^{v} / \partial \alpha & =-\frac{\partial D(\omega) / \partial \alpha}{\partial D(\omega) / \partial \varkappa_{c}}<0, \text { since } \\
\frac{\partial D(\omega)}{\partial \alpha} & =-\beta \frac{\varkappa_{c}(1-\beta)+\beta \theta(1-\beta \alpha)}{(1-\alpha \beta)(1-\beta)\left(1-\varkappa_{c}-\alpha \beta\right)}<0, \\
(b) \partial \varkappa_{c}^{v} / \partial \theta & =-\frac{\partial D(\omega) / \partial \theta}{\partial D(\omega) / \partial \varkappa_{c}}, \text { with } \\
\partial D(\omega) / \partial \theta & =\frac{\beta}{1-\beta} \ln \left[\frac{\left(1-\varkappa_{c}-\alpha \beta\right)(1-\beta \theta)}{1-\beta(1-\theta)}\right] .
\end{aligned}
$$

Let us consider the function $h\left(\theta ; \beta, \varkappa_{c}, \alpha\right)=\frac{\left(1-\varkappa_{c}-\alpha \beta\right)(1-\beta \theta)}{1-\beta(1-\theta)}-1$. It is easy to verify that: $(i) \partial h(\cdot) / \partial \theta=\left(1-\varkappa_{c}-\alpha \beta\right) \beta \frac{-2+\beta}{(1-\beta(1-\theta))^{2}}<0 \forall \theta$, since $\varkappa_{c}<$ $1-\alpha \beta$ and $(i i) h(\cdot)$ has a single root at $\theta^{*}=-\frac{\varkappa_{c}-\beta(1-\alpha)}{\beta\left(2-\varkappa_{c}-\alpha \beta\right)}<1-\alpha$, which shows the statement of the corollary 


\section{References}

[1] Aschauer, D.A. (1989). "Is Public Expenditure Productive?", Journal of Monetary Economics, 23, 177-200.

[2] Barro, R.J. (1990). "Government Spending in a Simple Model of Endogenous Growth", Journal of Political Economy, 98, 5, S103-S125.

[3] Caballé, J. and M. Santos (1993). "On Endogenous Growth with Physical and Human Capital", Journal of Political Economy, 101, 1042-1067.

[4] Caballé, J. (1998). "Growth Effects of Taxation under Altruism and Low Elasticity of Intertemporal Substitution", The Economic Journal, 108, 92-104.

[5] Chamley, C. (1986). "Optimal Taxation of Capital Income in General Equilibrium with Infinite Lives", Econometrica, 54 (3), 607-622.

[6] Chamley, C. (2001). "Capital Income Taxation, Wealth Distribution and Borrowing Constraints", Journal of Public Economics, 79, 55-69.

[7] Corsetti, G. and N. Roubini (1996). "Optimal Government Spending and Taxation in Endogenous Growth Models", NBER Working Paper 5851 .

[8] Fisher, W.H. and S.J. Turnovsky (1998). "Public Investment, Congestion and Private Capital Accumulation", The Economic Journal, 108, 399-413.

[9] Futagami, K., Y. Morita and A. Shibata (1993). "Dynamic Analysis of an Endogenous Growth Model with Public Capital", Scandinavian Journal of Economics, 95(4), 607-625.

[10] Glomm, G. and B. Ravikumar (1994). "Public Investment in Infrastructure in a Simple Growth Model", Journal of Economic Dynamics and Control, 18, 1173-1187.

[11] Glomm, G. and B. Ravikumar (1999). "Competitive Equilibrium and Public Investment Plans", Journal of Economic Dynamics and Control, $23,1207-1224$. 
[12] Jones, L.E. and R.E. Manuelli (1992). "Finite Lifetimes and Growth", Journal of Economic Theory, 58, 171-197.

[13] Jones, L.E., R.E. Manuelli and P.E. Rossi (1997). "On the Optimal Taxation of Capital Income", Journal of Economic Theory, 73, 93-117.

[14] Jones, L.E. and R.E. Manuelli (1997). "The Sources of Growth", Journal of Economic Dynamics and Control, 21, 75-114.

[15] Judd, K.L. (1985). "Redistributive Taxation in a Simple Perfect Foresight Model", Journal of Public Economics, 28, 59-83.

[16] Judd, K.L. (1999). "Optimal Taxation and Spending in General Competitive Growth Models", Journal of Public Economics, 71, 1-26.

[17] King R.G. and S. Rebelo (1988). "Production, Growth and Business Cycles, II: New Directions", Journal of Monetary Economics, 21, 309341.

[18] Lucas, R.E., Jr. (1990). "Supply-Side Economics: an Analytical Review", Oxford Economic Papers, 42, 293-316.

[19] Milesi-Ferretti, G.M. and N. Roubini (1998). "On the Taxation of Human and Physical Capital in Models of Endogenous Growth", Journal of Public Economics, 70, 237-254.

[20] Munnell, A. (1990). "How does Public Infrastructure Affect Regional Performance?", New England Economic Review, Sept./Oct., 11-32.

[21] Ramsey, F.P. (1927). "A Contribution to the Theory of Taxation", Economic Journal, 37, 47-61.

[22] Ratner, J.B. (1983). "Government Capital and the Production Function for the US Private Output", Economic Letters, 13, 213-217.7-48.

[23] Rebelo, S. (1991). "Long-run Policy Analysis and Long-run Growth", Journal of Political Economy, 99, 500-521.

[24] Romer, P.M. (1986). "Increasing Returns and Long-Run Growth", Journal of Political Economics, 94, 5, 1002-1037. 
[25] Romer, P.M. (1987). "Growth Based on Increasing Returns due to Specialization", American Economic Review, 77, 2, 56-62.

[26] Turnovsky, S.J. (1996). "Optimal Tax and Expenditure Policies in a Growing Economy", Journal of Public Economics, 60, 21-44.

[27] Turnovsky, S.J. (2000). "Fiscal Policy, Elastic Labor Supply and Endogenous Growth", Journal of Monetary Economics, 45, 185-210. 


\begin{tabular}{|c|c|c|c|c|}
\hline \multicolumn{5}{|c|}{ Table 4.1: Alternative benchmark calibrations } \\
\hline & bench 1 & bench 2 & bench 3 & bench 4 \\
\hline$\beta$ & 0.99 & 0.99 & 0.99 & 0.99 \\
\hline$\alpha$ & 0.40 & 0.75 & 0.40 & 0.70 \\
\hline$\theta$ & 0.15 & 0.15 & 0.35 & 0.30 \\
\hline$\phi$ & 0.45 & 0.10 & 0.25 & 0.00 \\
\hline
\end{tabular}

\begin{tabular}{|l|c|c|c|c|}
\hline \multicolumn{5}{|c|}{ Table 4.2: $\varkappa_{c}$-thresholds under growth and welfare-maximizing policies } \\
\hline & bench 1 & bench2 & bench3 & bench4 \\
\hline$\varkappa_{c}^{\gamma}$ & 60.4 & 24.9 & 59.2 & 25.9 \\
\hline$\varkappa_{i}^{d *}$ & 5.9 & 11.3 & 14.3 & 22.2 \\
\hline$\varkappa_{i}^{n *}$ & 0.0 & 0.9 & 1.2 & 4.8 \\
\hline$\varkappa_{c}^{v}$ & 60.3 & 24.3 & 58.8 & 24.5 \\
\hline$\varkappa_{i}^{d+}$ & 5.9 & 11.2 & 14.2 & 22.4 \\
\hline$\varkappa_{i}^{n+}$ & 0.1 & 1.4 & 1.6 & 6.0 \\
\hline
\end{tabular}

Note: For values of $\varkappa_{c}$ above $\varkappa_{c}^{\gamma}\left(\varkappa_{c}^{v}\right)$, the maximum long-run growth rate (welfare) is higher under income than under lump-sum taxes. $\varkappa_{i}^{d *}$ and $\varkappa_{i}^{d+}$ are the productive public investment-to-output ratios maximizing growth and welfare, respectively, under income taxes and for $\varkappa_{c}=\varkappa_{c}^{\gamma} \cdot \varkappa_{i}^{n *}$ is the supremum of the public investment ratio under lump-sum taxes for $\varkappa_{c}=\varkappa_{c}^{v}$. Growth is monotonic on $\varkappa_{i}$ in that case. $\varkappa_{i}^{n+}$ is the value of the ratio maximizing welfare under lump-sum taxes.

\begin{tabular}{|c|c|c|c|c|c|c|}
\hline \multicolumn{7}{|c|}{ Table 6.2: $\hat{\varkappa}_{c}^{\gamma}(\%)$ under alternative $\delta^{g}, \delta \in[0,1]$} \\
\hline$\delta^{g} \backslash \delta$ & 0 & .20 & .40 & .60 & .80 & 1 \\
\hline 0 & 25.48 & 25.32 & 25.20 & 25.09 & 24.90 & 24.90 \\
\hline .20 & 25.50 & 25.35 & 25.20 & 25.10 & 25.00 & 24.90 \\
\hline .40 & 25.50 & 25.36 & 25.21 & 25.10 & 25.00 & 24.90 \\
\hline .60 & 25.51 & 25.37 & 25.22 & 25.10 & 25.00 & 24.90 \\
\hline .80 & 25.52 & 25.38 & 25.24 & 25.10 & 25.01 & 24.90 \\
\hline 1 & 25.53 & 25.39 & 25.30 & 25.10 & 25.01 & 24.90 \\
\hline
\end{tabular}


Fig. 4.1: Growth-maximizing policies under lump-sum and income taxes

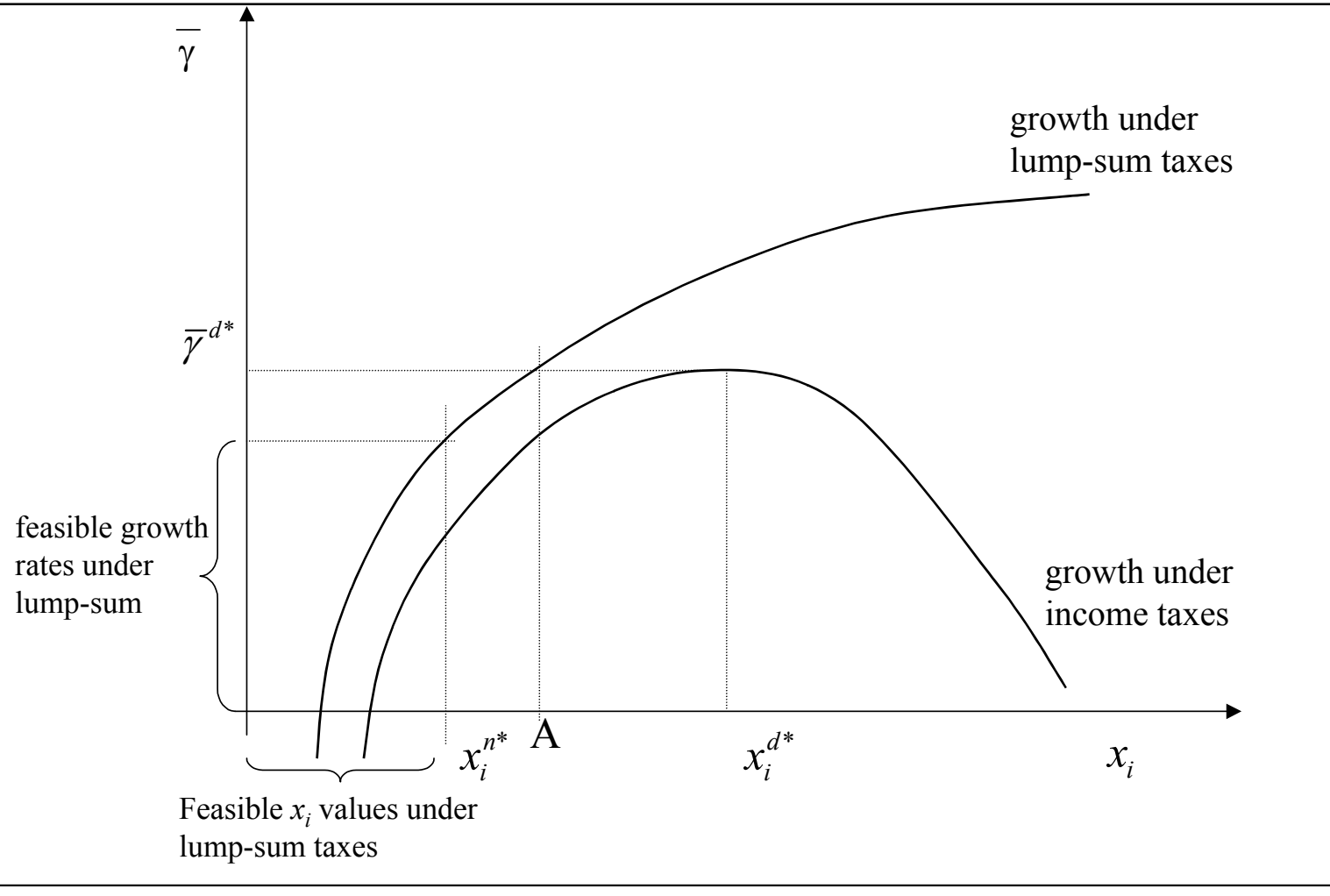

Note: $\varkappa_{i}^{d *}$ maximizes $\bar{\gamma}$ under income taxes and $\varkappa_{i}^{n *}$ is such that $\bar{c}=0$ under lump-sum taxes. If $\varkappa_{i}^{n *}$ is located to the left of $\mathrm{A}$, a higher growth rate could be achieved under income than under lump-sum taxes. 